\title{
Alcohol abstinence ameliorates the dysregulated immune profiles in patients with \\ alcoholic hepatitis: a prospective observational study
}

Wei Li ${ }^{1^{*}}$, Tohti Amet ${ }^{1 *}$, Yanyan Xing ${ }^{1}$, Dennis Yang ${ }^{1}$, Suthat Liangpunsakul ${ }^{2,3,4}$, Puneet Puri' ${ }^{5}$,

Patrick Kamath $^{6}$, Arun Sanyal ${ }^{5}$, Vijay Shah ${ }^{6}$, Barry Katz ${ }^{7}$, Svetlana Radaeva ${ }^{8}$, David Crabb ${ }^{2,9}$,

Naga Chalasani ${ }^{2}$, Qigui $Y u^{1}$

${ }^{1}$ Department of Microbiology and Immunology, Indiana University School of Medicine,

Indianapolis, IN 46202

${ }^{2}$ Division of Gastroenterology and Hepatology, Department of Medicine, Indiana University

School of Medicine, Indianapolis, IN 46202-5175

${ }^{3}$ Roudebush Veterans Administration Medical Center, Indianapolis, IN 46202

${ }^{4}$ Department of Biochemistry and Molecular Biology, Indiana University School of Medicine,

Indianapolis, IN 46202

${ }^{5}$ Division of Gastroenterology and Hepatology, Department of Medicine, Virginia Commonwealth

University, Richmond, VA 23298

${ }^{6}$ Division of Gastroenterology and Hepatology, Mayo Clinic, Rochester, MN 55905

${ }^{7}$ Department of Biostatistics, Indiana University School of Medicine and Richard M. Fairbanks

School of Public Health, Indianapolis, IN 46202

${ }^{8}$ National Institute of Alcoholism and Alcohol Abuse, National Institutes of Health, Rockville, MD,

${ }^{9}$ Internal Medicine, Eskenazi Health, Indianapolis, IN 46202

Keywords: immune-dysregulation, multiplex immunoassay, cross-sectional analysis,

longitudinal study, alcohol abstinence

Running title: Inflammatory and immunological profiles in patients with alcoholic hepatitis

This is the author's manuscript of the article published in final edited form as:

Li, W., Amet, T., Xing, Y., Yang, D., Liangpunsakul, S., Puri, P., Kamath, P., Sanyal, A., Shah, V., Katz, B., Radaeva, S., Crabb, D., Chalasani, N. and Yu, Q. (2017), Alcohol abstinence ameliorates the dysregulated immune profiles in patients with alcoholic hepatitis: A prospective observational study. Hepatology. Accepted Author Manuscript. http://dx.doi.org/10.1002/hep.29242 
${ }^{*}$ These authors contributed equally

Address correspondence to Dr. Qigui Yu, Department of Microbiology and Immunology, Indiana University School of Medicine, Medical Science Building MS457, 635 Barnhill Drive, Indianapolis, IN 46202, Email: andyu@iupui.edu, Tel: 317-274-2391, Fax: 317-278-3331.

\section{Abbreviations}

AH, alcoholic hepatitis; HDC, heavy drinking controls; HC, healthy controls; TNF, tumor necrosis factor; IL, interleukin; IP10, interferon gamma-induced protein 10; FGF-2, fibroblast growth factor 2; TGF- $\mathbf{\alpha}$, Transforming growth factor alpha; MDC, macrophage-derived chemokine; MHC, major histocompatibility complex; IFN, interferon; ALD, alcoholic liver disease; HCC, hepatocellular carcinoma; LPS, lipopolysaccharides; MCP, macrophage/monocyte chemotactic protein; MIP, macrophage inflammatory protein; TREAT, Translational Research and Evolving Alcoholic Hepatitis Treatment; AST, aspartate aminotransferase; NIAAA, National Institute on Alcohol Abuse and Alcoholism; ALT, alanine aminotransferase; PBMC, peripheral blood mononuclear cell; sCD40L, soluble CD40 ligand; EGF, epidermal growth factor; G-CSF, granulocyte-colony stimulating factor; GM-CSF, granulocyte-macrophage colony-stimulating factor; GRO, growth-regulated protein; VEGF, vascular endothelial growth factor; ELISA, enzyme-linked immunosorbent assay; ICS, intracellular staining; PFA, paraformaldehyde; MELD, end stage liver disease; INR, international normalized ratio; IQR, interquartile range; MFI, mean fluorescent intensity; Th, T helper cell; DC, dendritic cell; Treg, regulatory T cell; APC, antigen-presenting cell.

Authors have no conflict of interest to declare.

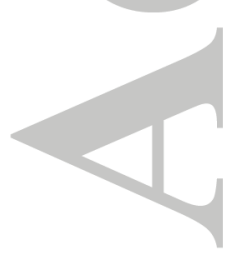




\section{Abstract}

Alcoholic hepatitis $(\mathrm{AH})$ develops only in small proportion of heavy drinkers. To better understand the mechanisms underlying this disparity, we conducted a study to define the relationship between $\mathrm{AH}$ development and dysregulated immune responses that might be ameliorated by alcohol abstinence. Sixty-eight $\mathrm{AH}$ patients, 65 heavy drinking controls without liver disease (HDC), and 20 healthy controls (HC) were enrolled and followed up to 12 months. At the baseline, HDC and HC had no significant differences in their plasma levels of 38 inflammatory cytokines/chemokines measured using multiplex immunoassays. However, compared to HDC, AH patients had higher baseline levels of 11 cytokines/chemokines (TNF- $\alpha$, IL-6, IL-8, IP10, IL-4, IL-9, IL-10, FGF-2, IL-7, IL-15, and TGF- $\alpha$ ), but lower levels of the antiinflammatory macrophage-derived chemokine (MDC). AH patients also had more activated, yet dysfunctional immune cells as monocytes, T cells, and B cells expressed higher levels of CD38 and CD69, but low levels of HLA-DR, CD80, and CD86 at baseline. In addition, CD4 T cells produced less IFN-ץ in response to T cell stimulation. Upregulated IL-6, IL-8, CD38, and CD69 and downregulated MDC, HLA-DR, CD86, and CD80 correlated positively and negatively, respectively, with disease severity. Longitudinal analysis indicated that levels of IL-6, IL-8, CD38, and CD69 were reduced, whereas levels of MDC, HLA-DR, CD80, and CD86 were increased in abstinent $\mathrm{AH}$ patients. All of the cellular immune abnormalities were reversed by day 360 in abstinent AH patients; however, plasma levels of TNF- $\alpha$, IL-8, IL-10, FGF-2, and IL-7 remained higher. Conclusion: AH patients were in a highly immune-dysregulated state, whereas HDC showed little evidence of immune activation. Alcohol abstinence reversed most, but not all, of the immunological abnormalities. 


\section{Introduction}

More than 2 billion people worldwide consume alcohol on a regular basis. Of these, approximately 76 million suffer from alcohol-related disorders (1). Long-term heavy drinkers develop a spectrum of severe alcoholic liver disease (ALD), ranging from alcoholic hepatitis $(\mathrm{AH})$, fibrosis/cirrhosis, to hepatocellular carcinoma (HCC) (2). $\mathrm{AH}$ is a severe and progressive liver inflammatory disease associated with significant morbidity and mortality, for which there are no effective medical therapies (3-5). Alcohol-induced dysregulation of both innate and adaptive immune systems has been implicated in the pathogenesis of $\mathrm{AH}(6-8)$.

Heavy alcohol consumption causes over-activation of innate immunity components in both the peripheral blood and the liver tissue by way of gut-derived bacterial toxins such as lipopolysaccharides (LPS) and the hepatic stress of alcohol metabolism $(9,10)$. Consequently, $\mathrm{AH}$ patients have elevated circulating levels of a variety of pro-inflammatory factors in association with elevated anti-inflammatory and hepatoprotective cytokines, such as IL-10 (11, 12). Studies have demonstrated that circulating levels of TNF- $\alpha, \mathrm{IL}-6, \mathrm{IL}-8, \mathrm{MCP}-1$, and MIP3 $\alpha$ correlate with the severity of AH and that two of them (TNF- $\alpha$ and IL-6) also correlate with $\mathrm{AH}$ mortality (13-16). Abstinence from alcohol improves clinical symptoms for most $\mathrm{AH}$ patients and has been shown to reduce IL-6 level $(17,18)$. Increased hepatic oxidative stress and over-activation of liver cells, including resident macrophages (Kupffer cells) and hepatocytes, have also been observed in $\mathrm{AH}$ patients $(9,10)$. These alternations increase infiltration of inflammatory cells including monocytes, neutrophils, and T cells into the liver, leading to liver damage $(16,19)$.

Alcohol abuse also impairs the adaptive immune system $(6,20)$. Studies in both humans and animal models have demonstrated that chronic alcohol abuse has a significant impact on $\mathrm{T}$ cell biology including a reduction in count, impairment of development and function, disturbance of the balance between effector and regulatory $T$ cell types, influence of phenotype and activation, and promotion of cell apoptosis $(6,20)$. Alcohol abuse also affects multiple aspects of B cell-mediated immunity $(6,21,22)$, leading to reduced numbers and function of B cells while 
simultaneously increasing production of immunoglobulins $(6,21,22)$. Particularly, the levels of autoantibodies against liver-specific antigens are increased in $\mathrm{AH}$ patients and may promote alcohol-related liver damage (6). Due to alcohol-induced impairment of both innate and adaptive immunity, chronic alcohol drinkers are more susceptible to many infectious pathogens with delayed infection recovery, thus extending hospital stays and increasing morbidity and mortality (23).

The reason why alcohol abuse causes $\mathrm{AH}$ in a subset of patients with excessive alcohol use and what determines the severity of $\mathrm{AH}$ has not yet been fully understood. Most previous studies have compared $\mathrm{AH}$ patients with healthy controls $(\mathrm{HC})$ or patients with clinically stable alcoholic cirrhosis to try to understand the immunological differences underlying the apparent individual susceptibility to $\mathrm{AH}$. We conducted a study to define the relationship between $\mathrm{AH}$ and dysregulated immune responses among heavy drinkers with or without $\mathrm{AH}$ and to investigate immune recovery associated with alcohol abstinence.

\section{Materials and Methods}

\section{Study Subjects and Blood Samples}

The sixty-eight $\mathrm{AH}$ patients and $65 \mathrm{HDC}$ included in this study were enrolled into the ongoing multicenter prospective Translational Research and Evolving Alcoholic Hepatitis Treatment 001 study (TREAT 001, NCT02172898). Demographic and clinical characterizations as well as drinking patterns of the study subjects are shown in Table 1. Detailed definitions of $\mathrm{AH}$ and $\mathrm{HDC}$ and the inclusion and exclusion criteria were previously described (24). Briefly, $\mathrm{AH}$ was defined as the onset of AST $>50 \mathrm{IU} / \mathrm{L}$ and elevated total bilirubin (initially $>2 \mathrm{mg} / \mathrm{dL}$ but amended to $>3 \mathrm{mg} / \mathrm{dL}$ ) (25) in patients with a long drinking history who were drinking heavily within the 6 weeks prior to enrollment. A liver biopsy was performed to confirm AH diagnosis in patients with uncertainty about drinking history or atypical clinical features. HDC were individuals with a comparable history of alcohol consumption but had no clinical evidence of 
liver disease (AST $\leq 50 \mathrm{U} / \mathrm{L}, \mathrm{ALT} \leq 50 \mathrm{U} / \mathrm{L}$, total bilirubin within normal limits) and were matched for age and sex. The study was approved by the Institutional Review Boards at Indiana University School of Medicine and Mayo Clinic. All participants provided a written informed consent.

Peripheral blood was collected in heparin-coated tubes (BD Biosciences, Franklin Lakes, NJ). Plasma and peripheral blood mononuclear cells (PBMCs) were isolated and stored at $80^{\circ} \mathrm{C}$ until use. Baseline $\mathrm{AH}$ samples were taken at presentation. For $\mathrm{AH}$ patients treated with corticosteroids and/or pentoxifylline, samples were taken within a few days of treatment. Some study subjects were fasting before the blood draw (Table 1). Plasma samples from 20 age- and sex-matched healthy volunteers without self-reported excessive drinking history were also included as $\mathrm{HC}$.

\section{Multiplex Immunoassays and Enzyme-linked Immunosorbent Assay (ELISA)}

Plasma concentrations of 38 cytokines/chemokines (sCD40L, EGF, Eotaxin, FGF-2, Flt-3

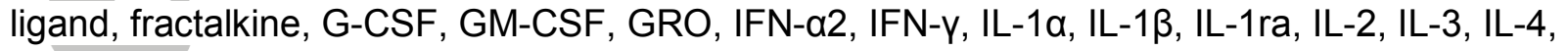
IL-5, IL-6, IL-7, IL-8, IL-9, IL-10, IL-12 (p40), IL-12 (p70), IL-13, IL-15, IL-17A, IP-10, MCP-1, MCP-3, MDC, MIP-1 $\alpha$, MIP-1 $\beta$, TGF- $\alpha$, TNF- $\alpha$, TNF- $\beta$, and VEGF) were simultaneously measured using a magnetic bead-based multiplex kit (HCYTMAG-60K-PX38, EMD Millipore, Billerica, MA). The concentrations of cytokines/chemokines were calculated using the Bio-Plex Manager v6.1 software (Bio-Rad, Hercules, CA). For statistical analyses, values below the detection limit of the assay were replaced with the minimal detectable concentrations for each analyte as provided by the manufacturer.

Plasma concentrations of IL-6, IL-8, and MDC were also measured using IL-6 and IL-8 High Sensitivity quantikine ELISA kits, and the Human CCL22/MDC DuoSet ELISA kit (R\&D Systems, Minneapolis, MN), respectively, to validate the multiplex immunoassay results.

\section{Flow Cytometry}


PBMCs were subjected to cell surface staining and intracellular staining (ICS) to determine leukocyte phenotype, activation, and immune response. For cell surface staining, PBMCs were incubated with fluorochrome-conjugated antibodies against CD4, CD8, CD14, CD16, CD19, CD38, CD69, CD80, CD86, and HLA-DR (Biolegend, San Diego, CA). Stained cells were fixed with $2 \%$ paraformaldehyde (PFA) and subsequently analyzed using a SORP FACSAria cytometer (BD Biosciences, San Jose, CA). For ICS, PBMCs were cultured for $24 \mathrm{~h}$ in complete RPMl 1640 medium containing $1 \mu \mathrm{g} / \mathrm{ml}$ of soluble anti-CD28 antibody (clone 28.1) and $20 \mathrm{U} / \mathrm{ml}$ human IL-2 in flat-bottomed 96-well plates pre-coated with $1 \mu \mathrm{g} / \mathrm{ml}$ of anti-CD3 antibody (clone OKT3). Brefeldin A (eBioscience, San Diego, CA) was added to a final concentration of $3 \mu \mathrm{M}$ for the last $6 \mathrm{~h}$ of incubation. Stimulated cells were stained with CD3, CD4, CD8, and IFN- $\gamma$ antibodies using the Cytofix/Cytoperm kit (BD Biosciences, San Jose, CA). Flow data were analyzed using FlowJo v10 software (Tree Star, San Carlos, CA).

\section{Statistical Analysis}

Differences in cross-sectional analysis for continuous variables between 2 groups were calculated using Mann Whitney test and Kruskal-Wallis test with Dunn's corrections for comparisons among 3 groups. Chi-square test was used for comparison between groups for categorical variables. The linear relationship between two variables was analyzed using the Spearman correlation test. Differences in longitudinal analysis were calculated using Friedman rank sum test with Dunn's corrections. $P<0.05$ was considered to be statistically significant.

\section{Results}

\section{Characteristics of the Study Cohort}

Table 1 shows characteristics of $\mathrm{AH}$ patients, HDC, and HC. Fasting rates at baseline and 6-month and one-year follow-up were similar between AH patients and HDC, but a higher percentage of HC were fasting as compared to HDC. Age and gender distributions and creatinine levels were comparable among the three groups. The HDC had significantly more 
drinks in the last 30 days before the enrollment than $\mathrm{AH}$ patients. As expected, the baseline MELD score and liver biochemistries (AST, ALT, and total bilirubin) were highly elevated in $\mathrm{AH}$ patients in comparison with HDC and HC. Prothrombin time was significantly increased in the AH patients than HDC. In addition, the median neutrophil counts were also significantly higher $(p<0.001)$ in $\mathrm{AH}$ patients $\left(6.35 \times 10^{9} / \mathrm{L}\right.$; interquartile range [IQR]: 4.1-15.0, $\left.\mathrm{n}=48\right)$ than in HDC (3.3×10\% /L; IQR: 2.5-4.5, n=56). Although HDC and HC had similar amounts of total bilirubin and AST, HDC had higher levels of ALT than HC. Thirty-nine AH patients were treated with corticosteroids and/or pentoxifylline (25 with steroids, 3 with pentoxifylline, and 11 with both) at the discretion of treating physicians. Fifteen $\mathrm{AH}$ patients (26\%) died within 6 months after recruitment. The complete abstinence rate was $64 \%$ and $72 \%$ for $\mathrm{AH}$ patients and $42 \%$ and $50 \%$ for HDC at days 180 and 360, respectively. The liver biochemistries markedly improved in $\mathrm{AH}$ patients and remained unchanged for HDC. However, the MELD scores, total bilirubin and AST, and prothrombin time remained abnormal in abstinent $\mathrm{AH}$ patients at 12 months (Supporting Table 1).

\section{AH Patients Had Dysregulated Plasma Levels of Pro-inflammatory and Anti-inflammatory Cytokines/Chemokines}

To assess immune characteristics in the peripheral blood from AH patients and HDC, we first performed multiplex immunoassays to quantify plasma levels of 38 human inflammatory cytokines/chemokines. Plasma samples from 20 healthy volunteers were used as $\mathrm{HC}$. The cross-sectional analysis results are summarized in Table 2 and Supporting Table 2. Compared to the HDC group, AH patients had significantly higher baseline plasma levels of 11 cytokines/chemokines including 4 pro-inflammatory cytokines/chemokines (TNF- $\alpha$, IL-6, IL-8, and IP10), 3 anti-inflammatory cytokines (IL-4, IL-9, and IL-10), and 4 growth factors (FGF-2, IL7, IL-15, and TGF- $\alpha$ ). IL-6 is a multifunctional cytokine that can have both pro-inflammatory and hepatoprotective effects in $\mathrm{AH}(12,26)$ and was classified as a pro-inflammatory cytokine in this study. At day 180, the 4 upregulated pro-inflammatory cytokines/chemokines (TNF-a, IL-6, IL-8, 
and IP10) remained significantly higher in AH patients than in HDC. At day 360, 3 proinflammatory cytokines (TNF- $\alpha$, IL-6, and IL-8) were still higher while 2 anti-inflammatory cytokines (IL-9 and IL-10) and 2 growth factors (FGF-2 and IL-7) were resumed among the 11 upregulated factors in $\mathrm{AH}$ patients. However, by day 180 and day 360, IL-6 and IL-8 levels greatly decreased from the baseline values in AH patients while remaining unchanged in HDC. Interestingly, MDC, an anti-inflammatory macrophage-derived chemokine, was the only cytokine/chemokine whose baseline level was significantly lower in $\mathrm{AH}$ patients than in HDC, but at day 360 MDC levels became higher in AH than in HDC. These results indicate that proinflammatory cytokines/chemokines decreased while anti-inflammatory factors increased in $\mathrm{AH}$ patients over the time of one-year observation.

We next compared baseline plasma levels of 38 cytokines/chemokines in AH patients and HDC with HC (Table 2 and Supporting Table 2). AH patients had significantly higher levels of TNF- $\alpha$, IL-6, IL-7, IL-8, IP-10, IL-10, IL-15, and TGF $\alpha$ at recruitment than HC. We also detected an additional cytokine (IFN $\alpha 2$ ) that was upregulated in $\mathrm{AH}$ patients. In contrast, the plasma levels of the 38 cytokines/chemokines analyzed were not significantly different between HDC and $\mathrm{HC}$.

We used IL-6 and IL-8 ELISAs to validate the multiplex results, as IL-6 and IL-8 were the most highly upregulated cytokines in AH patients (Supporting Table 2). ELISA data showed that IL-6 and IL-8 levels were significantly higher in AH patients than in HDC (Fig. 1A, 1B). In addition, cytokine levels measured by the two methods were significantly correlated (Fig. 1C). As MDC was a novel marker not previously identified in AH patients, we also quantified MDC levels by ELISA. We confirmed that MDC plasma levels were significantly lower and higher in $\mathrm{AH}$ patients than HDC at baseline and day 360 , respectively. Furthermore, MDC levels determined by the two techniques were significantly correlated (Fig. 1C).

Together, our data indicated that $\mathrm{AH}$ patients had a highly dysregulated and persistent production of inflammatory cytokines/chemokines as compared to HDC and HC, whereas HDC did not show evidence of inflammatory factors in comparison with $\mathrm{HC}$. 


\section{Cellular Markers of Immune Activation Were Highly Dysregulated in AH Patients}

As cytokines/chemokines regulate activation and function of both the innate and adaptive immune cells, we analyzed activation status of immune cells in PBMC samples from these subjects. Compared with HDC, monocytes from $\mathrm{AH}$ patients expressed higher levels of the activation markers CD38 and CD69 (\% and median fluorescent intensity, MFI), but lower levels of the antigen-presenting molecules MHC II HLA-DR (MFI) and the costimulatory molecules CD80 (\% and MFI) and CD86 (MFI) at baseline (Table 3 and Supporting Table 3). These results suggest that monocytes in AH patients are aberrantly activated and would have impaired capacity to activate antigen-specific T cells due to low expression of HLA-DR and costimulatory molecules. Further analyses demonstrated that $\mathrm{AH}$ patients still had significantly lower levels of CD80 (\% and MFI) and CD86 (MFI) at day 180, but by day 360 all these markers were similarly expressed on monocytes in both $\mathrm{AH}$ and HDC groups. The recovery expression of costimulatory molecules on monocytes in $\mathrm{AH}$ patients by day 360 is likely due to alcohol abstinence as majority of $\mathrm{AH}$ patients achieved alcohol abstinence by the time point. In fact, the results were similar to those obtained from the comparison between abstinent $\mathrm{AH}$ patients and HDC (data not shown).

We next compared T cell immunity in AH patients and HDC (Table 3 and Supporting Table 3). We found that baseline frequency of CD8 T cells was decreased in AH patients. In addition, $\mathrm{AH}$ patients had a higher \% of CD69-expressing CD4 and CD8 T cells, and a higher \% of CD38expressing CD8 T cells. At follow-up, expression of these T cell markers became comparable between $\mathrm{AH}$ and HDC groups. The frequency of CD69-expressing CD8 T cells remained higher in $\mathrm{AH}$ patients at day 360 , but this difference was not seen when comparing cells from abstinent $\mathrm{AH}$ patients and HDC (data not shown). We also examined the functional capacity of T cells to produce IFN- $\gamma$ in response to T cell receptor (TCR) stimulation, and found that the CD4 cells from $\mathrm{AH}$ patients produced significantly less IFN- $\gamma$ (Table 3 and Supporting Table 3). For B cells, 
CD80 expression ( $\%$ and $\mathrm{MFI}$ ) was reduced in $\mathrm{AH}$ patients at baseline, but there were no differences at follow-up time points.

Taken together, the peripheral blood immune cells in AH patients expressed higher levels of activation markers, but low levels of antigen-presentation and co-stimulatory molecules, and the CD4 T cells had reduced responses to TCR stimulation. All of the cellular immune abnormalities were reversed by day 360 with alcohol abstinence.

\section{Correlation of Immune Markers with Clinical Profiles of AH Patients}

To explore whether the differentially-expressed immune factors play a pathogenic role in $\mathrm{AH}$, we performed linear regression analysis to detect their correlation with disease severity represented by clinical scores (MELD score) and biochemical measurements (AST, ALT, total bilirubin, creatinine, and prothrombin time) in AH patients. Immunoprofiling data as well as neutrophil counts at enrolment and follow-ups were pooled for these analysis and the results are summarized in Supporting Table 4. Blood neutrophil counts had significantly correlations with multiple clinical indicators of disease severity (MELD score, total bilirubin, AST, and prothrombin time). IL-6 and IL-8 levels were highly correlated with clinical parameters such as MELD score. In addition, circulating levels of IL-8, a potent chemoattractant for neutrophils, were also strongly correlated with neutrophil counts (Spearman coefficient of $0.65, p<0.0001$ ). IL-15, TGF-a, and TNF-a showed significant but weak correlations with clinical parameters. MDC was negatively correlated with disease severity, as indicated by MELD score, total bilirubin, prothrombin time, and AST. Similarly, upregulated cellular activation markers (CD38 on monocytes and CD8 T cells, CD69 on both CD4 and CD8 T cells) were positively correlated with MELD score, total bilirubin, and AST. In contrast, downregulated cellular markers CD80, CD86, and HLA-DR on monocytes and CD80 on B cells showed negative correlations with MELD score, total bilirubin, and AST.

We next compared the baseline levels of immune parameters in $\mathrm{AH}$ patients who died within the 6-months and survivors to identify markers associated with 6-month mortality. The 
only marker that was differentially expressed was CD38 MFI on monocytes, with the nonsurvivors having lower levels (Supporting Fig. S1). Further, we investigated if any of the immunoparameters could predict survival by performing Kaplan-Meier survival analysis. Again, the only parameter that predicted 90-day or 180-day mortality was the level of CD38 expression (MFI) on monocytes (using MFI of 2999 as cut-off value). AH patients with lower CD38 expression had higher 90-day and 180-day mortality (Fig. 2A).

Thirty-nine of the $68 \mathrm{AH}$ patients were treated with the corticosteroid prednisone and/or pentoxifylline, two drugs that suppress inflammation in $\mathrm{AH}$ patients through different mechanisms. Corticosteroids reduce pro-inflammatory cytokines and increase anti-inflammatory cytokines, whereas pentoxifylline mainly inhibits TNF- $\alpha$ production. To determine how the steroid treatment impacted the immunoprofiles in $\mathrm{AH}$ patients, we compared immune markers in $\mathrm{AH}$ patients treated with prednisone alone or together with pentoxifylline and in untreated patients. As shown in Fig. 2B and Supporting Table 5, levels of IL-6, IL-7, IL-9, TNF- $\alpha$, IFN $\alpha 2$, G-CSF, and fractalkine were lower in the treated group. However, treated patients still had higher levels of inflammatory cytokines IL-8 and eotaxin, and lower MDC levels (Fig. 2B and Supporting Table 5). Treatment also improved T cell function as CD4 and CD8 T cells in treated patients had enhanced capacity to produce of IFN-Y in response to TCR stimulation. Interestingly, treated patients still had increased frequencies of CD38-expressing monocytes (Supporting Table 5). The remaining immune markers did not show differences between treated and untreated patients (Supporting Table 5 and data not shown).

We next examined whether treatment with corticosteroids had an impact on immune responses at follow-ups in alcohol abstinent $\mathrm{AH}$ patients. At days 180 and 360, levels of all immune markers except the frequency of CD38-expressing monocytes were similar between the treated and untreated patients (Supporting Table 5). It is pertinent to note that treated $\mathrm{AH}$ patients had higher MELD score, total bilirubin level, and longer prothrombin time, but similar levels of creatinine, AST, and ALT (Supporting Fig. S2), indicating that treated patients had more severe liver disease than untreated patients at the study entry. 
Taken together, our data suggested that corticosteroids reduced dysregulation of most but not all of the immune mediators and that steroid treatment did not appear to have additional long-term immunological benefits in alcohol abstinent $\mathrm{AH}$ patients.

\section{Longitudinal Analysis of Plasma Levels of Cytokines/Chemokines and Activation of Immune Cells in Alcohol Abstinent AH and HDC}

Longitudinal analysis of plasma levels of cytokines/chemokines showed that alcohol abstinent only ameliorated dysregulated levels of IL-8 and MDC in AH patients. As shown in Fig. 3A, plasma levels of IL-8 and MDC were significantly reduced and increased, respectively, in $\mathrm{AH}$ patients at day 180 versus baseline. Plasma levels of IL-8 still remained significantly lower and MDC levels remained higher (although was not significant) at day 360 versus baseline (Fig. 3A). IL-6 levels in AH patients trended to be lower during follow-up ( $p=0.08)$ (date not shown). IL-6, IL-8, and MDC levels in the HDC did not show longitudinal changes (Fig. 3B). Consistent with these finding that the majority of the 12 dysregulated cytokines/chemokines did not show significant longitudinal changes in alcohol abstinent $\mathrm{AH}$ patients, cross-sectional analysis of day-180 and day-360 follow-up samples from alcohol abstinent AH patients and HDC revealed that $\mathrm{AH}$ patients still had significantly higher levels of TNF- $\alpha$, IL-6, IL-8, and IP10 at day 180 and TNF- $\alpha$, IL-6, IL-8, IL-7 and FGF-2 at day 360 (Supporting Table 6).

We next examined longitudinal changes of the cell activation and costimulatory markers that were differentially expressed in AH patients and HDC. Expression levels of CD69 (\%) on CD4 T cells were significantly reduced in AH only at day 360 (Fig. 4A); expression of CD38 on monocytes (MFI) in AH trended to be lower during follow-up ( $p=0.085)$. Concurrently, CD80 levels on monocytes were increased by days 180 and 360 in AH patients, and CD86 and HLADR MFI on monocytes and CD80 MFI on B cells were also increased by day 360 (Fig. 4A and Supporting Fig. S3) in AH patients. Interestingly, monocytes from HDC also upregulated CD80 and CD86 expression at day 360 (Fig. 4B), suggesting that heavy drinking also led to phenotypical abnormalities in their monocytes at recruitment even in those without $\mathrm{AH}$. 
Together, our data indicated that the dysregulated cytokines/chemokines and cellular immune markers in $\mathrm{AH}$ patients as well as HDC improved with alcohol abstinence.

\section{Discussion}

In the present study, we performed a comprehensive cross-sectional and longitudinal analysis of soluble and cellular immune markers in the peripheral blood of a large cohort of $\mathrm{AH}$ patients and matched heavy drinkers without liver disease as well as healthy controls (Table 1). This is a major advantage of our study, as it can identify (1) changes related to heavy drinking alone, (2) changes that occur when AH develops, and (3) immune recovery following alcohol abstinence. We demonstrated that HDC had few indications of dysregulated immune profiles (Table 2). In contrast, AH patients exhibited a highly dysregulated production of cytokines/chemokines, immune cell activation, and neutrophilia when compared to HDC or HC (Tables 2, 3). We identified 11 upregulated cytokines/chemokines, including 4 pro-inflammatory cytokines (TNF- $\alpha$, IL-6, IL-8, and IP10), 3 anti-inflammatory cytokines (IL-4, IL-9, and IL-10), and 4 growth factors (FGF-2, IL-7, IL-15, and TGF- $\alpha$ ) and 1 downregulated chemokine (MDC) (Table 2). Both monocytes and T cells upregulated the cell activation markers CD38 and CD69, whereas monocytes and B cells downregulated the antigen-presenting molecules HLA-DR and the costimulatory molecules CD80 and CD86 (Table 3). Levels of upregulated IL-6, IL-8, CD38, CD69, and neutrophil count positively correlated with disease severity of $\mathrm{AH}$, whereas downregulated CD80, CD86, HLA-DR, and MDC showed negative correlations (Supporting Table 4). CD38 expression levels on monocytes predicted 3-month and 6-month mortality. Analysis of follow-up and longitudinal samples indicated the immune markers in $\mathrm{AH}$ patients drastically improved but were not completely recovered with alcohol abstinence, which is consistent with changes in their clinical profiles.

Of the 12 dysregulated cytokines/chemokines identified in our study, the pro-inflammatory cytokines/chemokines (TNF- $\alpha$, IL-6, IL-8, and IP10), the anti-inflammatory cytokines (IL-4 and IL-10), and the growth factor IL-15 have been shown to be elevated in patients with ALD in 
comparison to $\mathrm{HC}$ or those with stable alcoholic cirrhosis $(13,14,18,27,28)$. Serum IL-7 concentration is higher in alcohol-dependent individuals without clinical $\mathrm{AH}$ than $\mathrm{HC}(29)$. We found that IL-8, a potent neutrophil chemotactic factor, was the most highly upregulated cytokine in $\mathrm{AH}$ patients and remained higher in abstinent $\mathrm{AH}$ patients. In addition, IL-8 accumulation was more resistant to corticosteroid treatment than other pro-inflammatory cytokines, such as IL-6 and TNF- $\alpha$. IL-8 levels were highly correlated with disease severity and neutrophilia. Hepatic neutrophil infiltration and neutrophilia are prominent features of $\mathrm{AH}$, which correlate with disease severity (25). Future study on the relationship between IL-8 and activation/function of both circulating and hepatic neutrophils are warranted. Furthermore, our findings lend support to the blockade of IL-8 as a therapeutic strategy to reduce hepatic neutrophil infiltration and $\mathrm{AH}$ severity as demonstrated recently in an experimental ALD model (30).

We also identified 4 novel cytokines/chemokines (TGF- $\alpha$, FGF-2, IL-9, and MDC) that were differentially expressed in AH patients. TGF- $\alpha$ binding to its receptor EGFR (epidermal growth factor receptor) stimulates hepatocyte proliferation during liver regeneration after toxic liver injury (31). As TGF- $\alpha$ levels correlated with AH severity, upregulation of TGF-a might represent a failed attempt to repair liver damage through liver regeneration. Level of the multifunctional protein fibroblast growth factor 2 (FGF-2) increased with the progression of chronic liver diseases from chronic hepatitis to liver cirrhosis and HCC (32), and is implicated in hepatic fibrogenesis (33). The elevated levels of FGF-2 may reflect the observation that nearly all $\mathrm{AH}$ patients have some degree of fibrosis at diagnosis (34). IL-9 is mainly produced by Th9 and Th17 cells, two subsets of CD4 T cells. It is possible that enhanced levels of IL-9 in AH patients contribute to alcohol-induced intestinal permeability, as IL-9 impairs intestinal barrier functions in patients with ulcerative colitis (35).

MDC was downregulated in AH patients as compared to HDC. MDC is produced by dendritic cells (DCs) and macrophages, in particular, the activated anti-inflammatory and tissuerepairing M2 type of macrophages (36). Alcohol is known to suppress the differentiation of M2 macrophages and skew macrophages towards the pro-inflammatory M1 type in ALD patients, 
whereas M2 hepatic macrophages protect against ALD (37). MDC is a chemotactic ligand for the chemokine receptor CCR4, which is preferentially expressed on Th2 lymphocytes, skinhoming $T$ cells, and the immunosuppressive regulatory $T$ cells (Tregs) (38). MDC not only recruits Tregs to the sites of inflammation, it also activates and enhances Treg function (39). Interestingly, serum levels of MDC are also lower in patients with chronic inflammatory liver diseases such as primary sclerosing cholangitis, primary biliary cirrhosis, and autoimmune hepatitis than $\mathrm{HC}$ (38). We speculate that predominant M1 polarization in ALD leads to reduced production of MDC and subsequently fewer Tregs infiltrating the liver and more severe liver inflammation. Therefore, MDC augmentation may be explored as a potential new immune modulation therapy to attenuate $\mathrm{AH}$ and other inflammatory liver conditions.

The immunosuppressive cytokine IL-10 was among the highly upregulated circulatory factors in AH patients. IL-10 suppresses the production of pro-inflammatory cytokines by many cell types such as Kupffer cells, monocytes, and T cells. IL-10 also downregulates expression of HLA-DR, CD80, and CD86 on professional antigen-presenting cells (APCs), including monocytes/macrophages, DCs, and B cells, thereby impairing T cell activation. Indeed, the baseline expression levels of these molecules were greatly reduced on monocytes and B cells in $\mathrm{AH}$ patients. Thus, the increased level of IL10 may contribute to these changes in the circulating APCs. Alcohol has been shown to reduce CD80 and CD86 expression on DCs and DC co-stimulatory function (40). It is likely that reduced expression of HLA-DR, CD80, and CD86 on various APCs leads to suboptimal function of pathogen-specific T cells, which contributes to the discordance between heightened immune activation and increased susceptibility and severity to infections as observed in AH patients $(20,41,42)$.

Both monocytes and CD8 T cells in AH patients expressed significantly higher levels of CD38 (Tables 3 and Supporting Table 3). CD38 has diverse functions in T cell activation and proliferation, cytokine release, and monocyte chemotaxis towards sites of inflammation, and adhesion of $\mathrm{T}$ cells and monocytes to endothelial cells. As one of the pathophysiological features in $\mathrm{AH}$ patients is the accumulation of intrahepatic monocytes and T cells, we speculate 
that upregulation of CD38 on monocytes and CD8 T cells could play a role in the infiltration of activated circulating monocytes and T cells into the liver. Surprisingly, lower baseline CD38 expression level on monocytes was the only factor that predicted 3-month and 6-month mortality in $\mathrm{AH}$ patients (Fig. 2). As stated above, CD38 expressed on monocytes has multiple functions, including enhancing adherence to endothelial cells. It is possible that the hyper-adherence of activated monocytes to endothelium mediated by overexpression of CD38 impedes instead of promotes transmigration of monocytes from blood vessels towards the liver, causing less intrahepatic accumulation of macrophages, less liver damage, and lower mortality.

Alcohol abstinence, the most important aspect for ALD treatment, significantly improves the disease outcome and survival, but it does not lead to complete recovery in most ALD patients (2). Consistent with this result, clinical scores and liver function in our alcohol abstinent $\mathrm{AH}$ patients greatly improved, but were still abnormal during the follow-ups (Supporting Table 1). In addition, some of the upregulated cytokines, including the pro-inflammatory cytokines TNF- $\alpha$ and IL-8, were not normalized. The cellular markers appeared to be more responsive to alcohol withdraw, as they became similarly expressed between alcohol abstinent AH and HDC. Interestingly, monocytes in HDC upregulated CD80 and CD86 expression with alcohol abstinence, suggesting a subtle functional impairment of monocytes in the absence of other obvious clinical symptoms induced by excessive alcohol consumption.

At present, there are no effective medical interventions for $\mathrm{AH}$. Beside alcohol cessation, corticosteroids are the current pharmacologic options to treat severe $\mathrm{AH}$ patients. As corticosteroids cause immunosupression, $\mathrm{AH}$ patients receiving corticosteroids may be at higher risk of infections and have poor treatment outcomes $(4,5)$. Consistent with the lack of long-term clinical benefits of steroid treatment, we did not find additional immunological benefits in alcohol abstinent patients at follow-ups. It should be noted that the $\mathrm{AH}$ patients treated with steroids had more severe diseases than the untreated patients at the study entry.

In conclusion, we found that HDC showed little evidence of immune activation, whereas $\mathrm{AH}$ patients had a highly dysregulated expression of multiple immune markers. Abstinence from 
alcohol consumption greatly but not completely reversed immunological abnormalities, and steroid treatments did not appear to have additional long-term immunological benefits. Future network analysis of these and other dysregulated immune markers involved in multiple pathophysiological aspects of AH should shed light on key immune mediators that are most responsive to disease severity/mortality, steroid treatment, and alcohol abstinence (43), and provide clues for the development of pharmacological therapies to ameliorate dysregulated immune responses in $\mathrm{AH}$ patients.

\section{Acknowledgments}

We thank all volunteers for donating their time and blood for this multi-center prospective observational cohort study. Authors are particularly grateful to Ms. Megan Comerford, MPH, for her excellent managerial support of the TREAT consortium. This work was supported by the TREAT consortium that was created with the support of the National Institute on Alcohol Abuse and Alcoholism (NIAAA U01 AA021840, Translational Research and Evolving Alcoholic Hepatitis Treatment). Indiana University (NIAAA AA021883), Mayo Clinic (NIAAA AA021788), and Virginia Commonwealth University (NIAAA AA021891) are members of the TREAT consortium.

\section{References}

1. Anderson P. Global use of alcohol, drugs and tobacco. Drug Alcohol Rev 2006;25:489502.

2. O'Shea RS, Dasarathy S, McCullough AJ. Alcoholic liver disease. Hepatology 2010;51:307-328.

3. Grant BF, Dufour MC, Harford TC. Epidemiology of alcoholic liver disease. Semin Liver Dis 1988;8:12-25.

4. Chayanupatkul M, Liangpunsakul S. Alcoholic hepatitis: a comprehensive review of pathogenesis and treatment. World J Gastroenterol 2014;20:6279-6286.

5. Saberi B, Dadabhai AS, Jang YY, Gurakar A, Mezey E. Current Management of Alcoholic Hepatitis and Future Therapies. J Clin Transl Hepatol 2016;4:113-122.

$6 . \quad$ Pasala S, Barr T, Messaoudi I. Impact of Alcohol Abuse on the Adaptive Immune System. Alcohol Res 2015;37:185-197.

7. Gao B, Seki E, Brenner DA, Friedman S, Cohen JI, Nagy L, Szabo G, et al. Innate immunity in alcoholic liver disease. Am J Physiol Gastrointest Liver Physiol 2011;300:G516-525. 
8. Miller AM, Horiguchi N, Jeong WI, Radaeva S, Gao B. Molecular mechanisms of alcoholic liver disease: innate immunity and cytokines. Alcohol Clin Exp Res 2011;35:787-793. 9. Bode C, Bode JC. Activation of the innate immune system and alcoholic liver disease: effects of ethanol per se or enhanced intestinal translocation of bacterial toxins induced by ethanol? Alcohol Clin Exp Res 2005;29:166S-171S.

10. Gao B, Bataller R. Alcoholic liver disease: pathogenesis and new therapeutic targets. Gastroenterology 2011;141:1572-1585.

11. Neuman MG, Maor Y, Nanau RM, Melzer E, Mell H, Opris M, Cohen L, et al. Alcoholic Liver Disease: Role of Cytokines. Biomolecules 2015;5:2023-2034.

12. Gao B. Hepatoprotective and anti-inflammatory cytokines in alcoholic liver disease. J Gastroenterol Hepatol 2012;27 Suppl 2:89-93.

13. Rachakonda V, Gabbert C, Raina A, Li H, Malik S, DeLany JP, Behari J. Stratification of risk of death in severe acute alcoholic hepatitis using a panel of adipokines and cytokines. Alcohol Clin Exp Res 2014;38:2712-2721.

14. Gonzalez-Quintela A, Vidal C, Lojo S, Perez LF, Otero-Anton E, Gude F, Barrio E. Serum cytokines and increased total serum IgE in alcoholics. Ann Allergy Asthma Immunol 1999;83:61-67.

15. Bird GL, Sheron N, Goka AK, Alexander GJ, Williams RS. Increased plasma tumor necrosis factor in severe alcoholic hepatitis. Ann Intern Med 1990;112:917-920.

16. Degre D, Lemmers A, Gustot T, Ouziel R, Trepo E, Demetter P, Verset L, et al. Hepatic expression of CCL2 in alcoholic liver disease is associated with disease severity and neutrophil infiltrates. Clin Exp Immunol 2012;169:302-310.

17. Chatzipanagiotou S, Kalykaki M, Tzavellas E, Karaiskos D, Paparrigopoulos T, Liappas A, Nicolaou C, et al. Alteration of biological markers in alcohol-dependent individuals without liver disease during the detoxification therapy. In Vivo 2010;24:325-328.

18. Khoruts A, Stahnke L, McClain CJ, Logan G, Allen JI. Circulating tumor necrosis factor, interleukin-1 and interleukin-6 concentrations in chronic alcoholic patients. Hepatology 1991;13:267-276.

19. Jampana SC, Khan R. Pathogenesis of alcoholic hepatitis: Role of inflammatory signaling and oxidative stress. World J Hepatol 2011;3:114-117.

20. Chan C, Levitsky J. Infection and Alcoholic Liver Disease. Clin Liver Dis 2016;20:595606.

21. Matos LC, Batista P, Monteiro N, Ribeiro J, Cipriano MA, Henriques P, Girao F, et al. Lymphocyte subsets in alcoholic liver disease. World J Hepatol 2013;5:46-55.

22. Cook RT, Waldschmidt TJ, Cook BL, Labrecque DR, McLatchie K. Loss of the CD5+ and CD45RAhi B cell subsets in alcoholics. Clin Exp Immunol 1996;103:304-310.

23. Curtis BJ, Zahs A, Kovacs EJ. Epigenetic targets for reversing immune defects caused by alcohol exposure. Alcohol Res 2013;35:97-113.

24. Liangpunsakul S, Puri P, Shah VH, Kamath P, Sanyal A, Urban T, Ren X, et al. Effects of Age, Sex, Body Weight, and Quantity of Alcohol Consumption on Occurrence and Severity of Alcoholic Hepatitis. Clin Gastroenterol Hepatol 2016.

25. Crabb DW, Bataller R, Chalasani NP, Kamath PS, Lucey M, Mathurin P, McClain C, et al. Standard Definitions and Common Data Elements for Clinical Trials in Patients With Alcoholic Hepatitis: Recommendation From the NIAAA Alcoholic Hepatitis Consortia. Gastroenterology 2016;150:785-790.

26. Li M, He Y, Zhou Z, Ramirez T, Gao Y, Gao Y, Ross RA, et al. MicroRNA-223 ameliorates alcoholic liver injury by inhibiting the IL-6-p47phox-oxidative stress pathway in neutrophils. Gut 2016.

27. Gonzalez-Reimers E, Fernandez-Rodriguez CM, Santolaria-Fernandez F, de la VegaPrieto MJ, Martin-Gonzalez C, Gomez-Rodriguez MA, Aleman-Valls MR, et al. Interleukin-15 and other myokines in chronic alcoholics. Alcohol Alcohol 2011;46:529-533.

28. Hill DB, Marsano LS, McClain CJ. Increased plasma interleukin-8 concentrations in alcoholic hepatitis. Hepatology 1993;18:576-580. 
29. Nikou T, loannidis A, Zoga M, Tzavellas E, Paparrigopoulos T, Magana M, Pliatsika P, et al. Alteration in the concentrations of Interleukin-7 (IL-7), Interleukin-10 (IL-10) and Granulocyte Colony Stimulating Factor (G-CSF) in alcohol-dependent individuals without liver disease, during detoxification therapy. Drug Alcohol Depend 2016;163:77-83.

30. Wieser V, Adolph TE, Enrich B, Kuliopulos A, Kaser A, Tilg H, Kaneider NC. Reversal of murine alcoholic steatohepatitis by pepducin-based functional blockade of interleukin-8 receptors. Gut 2016.

31. Webber EM, FitzGerald MJ, Brown PI, Bartlett MH, Fausto N. Transforming growth factor-alpha expression during liver regeneration after partial hepatectomy and toxic injury, and potential interactions between transforming growth factor-alpha and hepatocyte growth factor. Hepatology 1993;18:1422-1431.

32. Jin-no K, Tanimizu M, Hyodo I, Kurimoto F, Yamashita T. Plasma level of basic

fibroblast growth factor increases with progression of chronic liver disease. J Gastroenterol 1997;32:119-121.

33. Yu C, Wang F, Jin C, Huang X, Miller DL, Basilico C, McKeehan WL. Role of fibroblast growth factor type 1 and 2 in carbon tetrachloride-induced hepatic injury and fibrogenesis. Am J Pathol 2003;163:1653-1662.

34. Bataller R, Brenner DA. Liver fibrosis. J Clin Invest 2005;115:209-218.

35. Gerlach K, Hwang Y, Nikolaev A, Atreya R, Dornhoff H, Steiner S, Lehr HA, et al. TH9 cells that express the transcription factor PU.1 drive T cell-mediated colitis via IL-9 receptor signaling in intestinal epithelial cells. Nat Immunol 2014;15:676-686.

36. Jaguin M, Houlbert N, Fardel O, Lecureur V. Polarization profiles of human M-CSFgenerated macrophages and comparison of M1-markers in classically activated macrophages from GM-CSF and M-CSF origin. Cell Immunol 2013;281:51-61.

37. Wan J, Benkdane M, Teixeira-Clerc F, Bonnafous S, Louvet A, Lafdil F, Pecker F, et al. M2 Kupffer cells promote M1 Kupffer cell apoptosis: a protective mechanism against alcoholic and nonalcoholic fatty liver disease. Hepatology 2014;59:130-142.

38. Yoshie O, Matsushima K. CCR4 and its ligands: from bench to bedside. Int Immunol 2015;27:11-20.

39. Bischoff L, Alvarez S, Dai DL, Soukhatcheva G, Orban PC, Verchere CB. Cellular mechanisms of CCL22-mediated attenuation of autoimmune diabetes. J Immunol 2015;194:3054-3064.

40. Mandrekar P, Catalano D, Dolganiuc A, Kodys K, Szabo G. Inhibition of myeloid dendritic cell accessory cell function and induction of T cell anergy by alcohol correlates with decreased IL-12 production. J Immunol 2004;173:3398-3407.

41. Szabo G, Mandrekar P. A recent perspective on alcohol, immunity, and host defense. Alcohol Clin Exp Res 2009;33:220-232.

42. Wang HJ, Gao B, Zakhari S, Nagy LE. Inflammation in alcoholic liver disease. Annu Rev Nutr 2012;32:343-368.

43. Zamora R, Vodovotz Y, Mi Q, Barclay D, Yin J, Horslen S, Rudnick D, et al. Data-Driven Modeling for Precision Medicine in Pediatric Acute Liver Failure. Mol Med 2016;22. 
Table 1. Comparison of Characteristics of AH patients and HDC in the TREAT Study Cohort

\begin{tabular}{|c|c|c|c|c|c|c|c|c|c|c|}
\hline 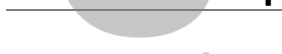 & & ay 0 (ba & eline) & & & ay 180 & & & ay 360 & \\
\hline Variable & $\begin{array}{c}\mathrm{HC} \\
(n=20)\end{array}$ & $\underset{(n=68)}{\mathrm{AH}}$ & $\begin{array}{l}\mathrm{HDC} \\
(n=61)\end{array}$ & $p$ & $\begin{array}{c}\mathrm{AH} \\
(n=28)\end{array}$ & $\begin{array}{l}\mathrm{HDC} \\
(n=33)\end{array}$ & $p$ & $\underset{(n=18)}{\mathrm{AH}}$ & $\begin{array}{l}\mathrm{HDC} \\
(n=26)\end{array}$ & $p$ \\
\hline $\begin{array}{l}\text { Age at enrollment } \\
\text { (years) }\end{array}$ & $\begin{array}{c}38 \\
(27-53)\end{array}$ & $\begin{array}{c}44 \\
(35-52)\end{array}$ & $\begin{array}{c}43 \\
(36-52)\end{array}$ & ns & $\begin{array}{c}45 \\
(38-53)\end{array}$ & $\begin{array}{c}46 \\
(37-53)\end{array}$ & ns & $\begin{array}{c}40 \\
(33-53)\end{array}$ & $\begin{array}{c}48 \\
(39-55)\end{array}$ & ns \\
\hline $\begin{array}{l}\text { Gender } \\
\text { (\% Male) }\end{array}$ & 55 & 61 & 57 & ns & 57 & 59 & ns & 61 & 60 & ns \\
\hline $\begin{array}{l}\text { Total drinks in } 30 \\
\text { days }\end{array}$ & & $\begin{array}{c}238 \\
(98-360)\end{array}$ & $\begin{array}{c}300 \\
(198-508)\end{array}$ & $* *$ & $\begin{array}{c}0 \\
(0-8)\end{array}$ & $\begin{array}{c}0 \\
(0-56)\end{array}$ & ns & $\begin{array}{c}0 \\
(0-2)\end{array}$ & $\begin{array}{c}1 \\
(0-98)\end{array}$ & ns \\
\hline $\begin{array}{l}\text { Total drinking } \\
\text { days in } 30 \text { days }\end{array}$ & & $\begin{array}{c}27 \\
(17-30)\end{array}$ & $\begin{array}{c}27 \\
(23-30)\end{array}$ & ns & $\begin{array}{c}0 \\
(0-2)\end{array}$ & $\begin{array}{c}0 \\
(0-16)\end{array}$ & ns & $\begin{array}{c}0 \\
(0-2)\end{array}$ & $\begin{array}{c}1 \\
(0-23)\end{array}$ & ns \\
\hline $\begin{array}{l}\text { Complete } \\
\text { abstinence (\%) }\end{array}$ & & & & & 64 & 42 & ns & 72 & 50 & ns \\
\hline MELD score & & $\begin{array}{c}24 \\
(19-27)\end{array}$ & $\begin{array}{c}6 \\
(6-7)\end{array}$ & $* * *$ & $\begin{array}{c}12 \\
(8-14)\end{array}$ & $\begin{array}{c}7 \\
(6-8)\end{array}$ & $* * *$ & $\begin{array}{c}11 \\
(8-13)\end{array}$ & $\begin{array}{c}7 \\
(6-8)\end{array}$ & $* * *$ \\
\hline $\begin{array}{l}\text { Creatinine } \\
\text { (mg/dL) }\end{array}$ & $\begin{array}{c}0.86 \\
(0.78-1.02)\end{array}$ & $\begin{array}{c}0.75 \\
(0.58-1.06)\end{array}$ & $\begin{array}{c}0.79 \\
(0.66-0.9)\end{array}$ & ns & $\begin{array}{c}0.78 \\
(0.6-1)\end{array}$ & $\begin{array}{c}0.91 \\
(0.77-1.07)\end{array}$ & ns & $\begin{array}{c}0.98 \\
(0.64-1.18)\end{array}$ & $\begin{array}{c}0.97 \\
(0.83-1.10)\end{array}$ & ns \\
\hline $\begin{array}{l}\text { Total bilirubin } \\
(\mathrm{mg} / \mathrm{dL})\end{array}$ & $\begin{array}{c}0.5^{\mathrm{F \#}} \\
(0.3-0.6)\end{array}$ & $\begin{array}{c}12.9 \\
(7-19.6)\end{array}$ & $\begin{array}{c}0.6 \\
(0.4-0.7)\end{array}$ & $* * *$ & $\begin{array}{c}1.5 \\
(0.8-3.4)\end{array}$ & $\begin{array}{c}0.4 \\
(0.3-0.5)\end{array}$ & $* * *$ & $\begin{array}{c}1.2 \\
(0.7-1.8)\end{array}$ & $\begin{array}{c}0.4 \\
(0.3-0.7)\end{array}$ & ** \\
\hline $\begin{array}{l}\text { Prothrombin time } \\
\text { (INR) }\end{array}$ & nd & $\begin{array}{c}1.78 \\
(1.40-2.04)\end{array}$ & $\begin{array}{c}0.96 \\
(0.92-1.01)\end{array}$ & $* * *$ & $\begin{array}{c}1.2 \\
(1.16-1.47)\end{array}$ & $\begin{array}{c}1.01 \\
(0.95-1.04)\end{array}$ & $* * *$ & $\begin{array}{c}1.22 \\
(1.07-1.45)\end{array}$ & $\begin{array}{c}0.97 \\
(0.95-1.06)\end{array}$ & $* * *$ \\
\hline AST (IU/L) & $\begin{array}{c}17^{\# \#} \\
(16-21)\end{array}$ & $\begin{array}{c}113 \\
(88-146)\end{array}$ & $\begin{array}{c}24 \\
(18-29)\end{array}$ & $* * *$ & $\begin{array}{c}48 \\
(32-70)\end{array}$ & $\begin{array}{c}20 \\
(16-23)\end{array}$ & $* * *$ & $\begin{array}{c}35 \\
(28-57)\end{array}$ & $\begin{array}{c}21 \\
(17-26)\end{array}$ & $* *$ \\
\hline ALT (IU/L) & $\begin{array}{c}13^{\# \#} \\
(8-18)\end{array}$ & $\begin{array}{c}46 \\
(30-59)\end{array}$ & $\begin{array}{c}22 \S \S \\
(16-28)\end{array}$ & $* * *$ & $\begin{array}{c}30 \\
(20-43)\end{array}$ & $\begin{array}{c}15.5 \\
(11-22)\end{array}$ & $* \star *$ & $\begin{array}{c}24.5 \\
(22-34)\end{array}$ & $\begin{array}{c}17.5 \\
(13-27)\end{array}$ & ns \\
\hline $\begin{array}{l}\text { Treatment with } \\
\text { PDN and/or PTX }\end{array}$ & & $58 \%$ & $0 \%$ & & $60 \%$ & $0 \%$ & & $56 \%$ & $0 \%$ & \\
\hline Fasting & $30 \%{ }^{\#}$ & $15 \%$ & $5 \% \S \S$ & ns & $29 \%$ & $44 \%$ & ns & $11 \%$ & $35 \%$ & ns \\
\hline
\end{tabular}

Note: Data are represented as median (interquartile range). $\mathrm{HC}$, healthy controls; $\mathrm{AH}$, patients with alcoholic hepatitis; HDC, heavy drinking controls; MELD, end stage liver disease; INR, international normalized ratio; AST, aspartate aminotransferase; ALT, alanine aminotransferase; PDN, prednisone; PTX, pentoxifylline. Kruskal-Wallis test with Dunn's correction for pairwise comparisons of continuous variables among $\mathrm{HC}, \mathrm{AH}$ patients and $\mathrm{HDC}$ at enrolment (Day 0). Mann Whitney test comparing AH patients versus HDC at Day 180 and Day 360. Chi-square test for analysis of categorical variables. ${ }^{*} p<0.05,{ }^{* *} p<0.01,{ }^{* *} p<0.001$ for comparison between $\mathrm{AH}$ patients and $\mathrm{HDC} ;{ }^{\neq \neq} p<0.01,{ }^{\neq \neq \neq} p<0.001$ for comparison between $\mathrm{AH}$ patients and $\mathrm{HC}$ at Day $0 ; \S p<0.01$ for comparison between HDC and HC at Day 0; ns, not significant. 
Table 2. Comparison of Plasma Levels of Cytokines/Chemokines in AH patients, HDC, and HC

\begin{tabular}{|c|c|c|c|c|c|c|c|c|}
\hline \multicolumn{2}{|c|}{ Cytokines/chemokines } & \multicolumn{3}{|c|}{ Day 0} & \multicolumn{2}{|c|}{ Day 180} & \multicolumn{2}{|c|}{ Day 360} \\
\hline $\mathrm{T}_{\mathrm{y}}$ & Names & $\begin{array}{c}\mathrm{HC} \\
\mathrm{n}=20\end{array}$ & $\begin{array}{c}\mathrm{AH} \\
\mathrm{n}=65\end{array}$ & $\begin{array}{l}\mathrm{HDC} \\
\mathrm{n}=61\end{array}$ & $\begin{array}{c}\mathrm{AH} \\
\mathrm{n}=28\end{array}$ & $\begin{array}{l}\mathrm{HDC} \\
\mathrm{n}=32\end{array}$ & $\begin{array}{c}\mathrm{AH} \\
\mathrm{n}=17\end{array}$ & $\begin{array}{l}\mathrm{HDC} \\
\mathrm{n}=26\end{array}$ \\
\hline \multirow{5}{*}{$\begin{array}{l}\text { Pro- } \\
\text { inflammatory }\end{array}$} & IFN $\alpha 2$ & $\begin{array}{c}34.5^{\#} \\
(14-55.7)\end{array}$ & $\begin{array}{c}74.1 \\
(51.9-115.6)\end{array}$ & $\begin{array}{c}54.9 \\
(15.3-88.2)\end{array}$ & $\begin{array}{c}73.0 \\
(33.1-92.8)\end{array}$ & $\begin{array}{c}80.2 \\
(38.7-97.4)\end{array}$ & $\begin{array}{c}93.4 \\
(54.9-147.2)\end{array}$ & $\begin{array}{c}73.0 \\
(56.8-92.7)\end{array}$ \\
\hline & $\mathrm{TNF} \alpha$ & $\begin{array}{c}6.5^{\#} \\
(4.8-10)\end{array}$ & $\begin{array}{c}17.9^{\star * *} \\
(12.5-35.8)\end{array}$ & $\begin{array}{c}10.2 \\
(6.8-19.2)\end{array}$ & $\begin{array}{c}19.9^{*} \\
(10.6-31.1)\end{array}$ & $\begin{array}{c}9.8 \\
(6.6-22.8)\end{array}$ & $\begin{array}{c}25.3^{\star * *} \\
(21.8-36.9)\end{array}$ & $\begin{array}{c}14.0 \\
(7.3-20.8)\end{array}$ \\
\hline & IL-6 & $\begin{array}{c}1.4^{\# \#} \\
(0.9-3.3)\end{array}$ & $\begin{array}{c}13.5^{\star \star *} \\
(6.6-36.2)\end{array}$ & $\begin{array}{c}2.6 \\
(0.9-6)\end{array}$ & $\begin{array}{c}7.0^{*} \\
(3-15.8)\end{array}$ & $\begin{array}{c}4.8 \\
(2.2-7.8)\end{array}$ & $\begin{array}{c}7.8^{\star *} \\
(5-14.4)\end{array}$ & $\begin{array}{c}2.5 \\
(0.9-5.1)\end{array}$ \\
\hline & IL-8 & $\begin{array}{c}6.9^{\#} \\
(4.9-16.7)\end{array}$ & $\begin{array}{c}314.2^{* \star \star} \\
(117.9-608.4)\end{array}$ & $\begin{array}{c}8.0 \\
(4.7-15.2)\end{array}$ & $\begin{array}{c}52.2^{* * *} \\
(23.3-102.5)\end{array}$ & $\begin{array}{c}8.4 \\
(5.7-31.6)\end{array}$ & $\begin{array}{c}50.9^{* * *} \\
(25.7-111.4)\end{array}$ & $\begin{array}{c}11.0 \\
(5.3-16.2)\end{array}$ \\
\hline & IP10 & $\begin{array}{c}507^{\#} \\
(344-610)\end{array}$ & $\begin{array}{c}1144^{\star \star \star} \\
(767-1531)\end{array}$ & $\begin{array}{c}629 \\
(429-847) \\
\end{array}$ & $\begin{array}{c}1046^{* *} \\
(777-1682)\end{array}$ & $\begin{array}{c}639 \\
(409-972)\end{array}$ & $\begin{array}{c}1170 \\
(861-1388)\end{array}$ & $\begin{array}{c}790(570- \\
1315)\end{array}$ \\
\hline \multirow{4}{*}{$\begin{array}{l}\text { Anti- } \\
\text { inflammatroy }\end{array}$} & IL-4 & $\begin{array}{c}4.5 \\
(4.5-14.7)\end{array}$ & $\begin{array}{c}4.5^{*} \\
(4.5-17)\end{array}$ & $\begin{array}{c}4.5 \\
(4.5-7.1)\end{array}$ & $\begin{array}{c}4.5 \\
(4.5-18.4)\end{array}$ & $\begin{array}{c}4.5 \\
(4.5-9.8)\end{array}$ & $\begin{array}{c}10.3 \\
(4.5-31.7)\end{array}$ & $\begin{array}{c}4.5 \\
(4.5-9.3)\end{array}$ \\
\hline & IL-9 & $\begin{array}{c}1.4 \\
(1.2-5.7)\end{array}$ & $\begin{array}{c}1.4^{*} \\
(1.2-5.8)\end{array}$ & $\begin{array}{c}1.2 \\
(0.6-3.6)\end{array}$ & $\begin{array}{c}2.3 \\
(0.6-5.6)\end{array}$ & $\begin{array}{c}1.2 \\
(1.2-3.2)\end{array}$ & $\begin{array}{c}4.1^{*} \\
(1.2-15.3)\end{array}$ & $\begin{array}{c}1.2 \\
(1.2-2.7)\end{array}$ \\
\hline & IL-10 & $\begin{array}{c}2.7^{\# \prime} \\
(1.6-5.6)\end{array}$ & $\begin{array}{c}14.3^{* * *} \\
(6.4-35.2)\end{array}$ & $\begin{array}{c}5.6 \\
(1.8-10.3)\end{array}$ & $\begin{array}{c}9.9 \\
(2.8-26.1)\end{array}$ & $\begin{array}{c}9.3 \\
(1.2-12.7)\end{array}$ & $\begin{array}{c}17.6^{*} \\
(10.9-34.2)\end{array}$ & $\begin{array}{c}9.5 \\
(3.7-15.8)\end{array}$ \\
\hline & MDC & $\begin{array}{c}889 \\
(768-1091)\end{array}$ & $\begin{array}{c}645^{\star \star \star} \\
(367-1237)\end{array}$ & $\begin{array}{c}1167(795- \\
1445)\end{array}$ & $\begin{array}{c}1409 \\
(1052-1956)\end{array}$ & $\begin{array}{c}1191 \\
(776-1626)\end{array}$ & $\begin{array}{c}2552^{*} \\
(1137-2907)\end{array}$ & $\begin{array}{c}1296 \\
(857-1796)\end{array}$ \\
\hline \multirow{5}{*}{$\begin{array}{l}\text { Growth } \\
\text { factors }\end{array}$} & EGF & $\begin{array}{c}50.9^{\#} \\
(29-102)\end{array}$ & $\begin{array}{c}22.8 \\
(11.6-42.9)\end{array}$ & $\begin{array}{c}29.4 \\
(15.2-50.8)\end{array}$ & $\begin{array}{c}33.5 \\
(13.1-59)\end{array}$ & $\begin{array}{c}34.6 \\
(17.2-71.5)\end{array}$ & $\begin{array}{c}42.1 \\
(28.4-118)\end{array}$ & $\begin{array}{c}40.2 \\
(8.5-83)\end{array}$ \\
\hline & FGF2 & $\begin{array}{c}81.6 \\
(54.1-133.1)\end{array}$ & $\begin{array}{c}66.3^{*} \\
(49.3-136.7)\end{array}$ & $\begin{array}{c}56 \\
(26.4-95.9)\end{array}$ & $\begin{array}{c}89.8 \\
(41.7-124.6)\end{array}$ & $\begin{array}{c}92.8 \\
(43.1-117)\end{array}$ & $\begin{array}{c}155.0^{* *} \\
(91.9-225.3)\end{array}$ & $\begin{array}{c}80.5 \\
(55-112.1)\end{array}$ \\
\hline & IL-7 & $\begin{array}{c}1.4^{\ddagger} \\
(1.4-3.3)\end{array}$ & $\begin{array}{c}8.1^{*} \\
(1.4-15.2)\end{array}$ & $\begin{array}{c}2.1 \\
(1.4-9.7)\end{array}$ & $\begin{array}{c}7.0 \\
(1.4-11.2)\end{array}$ & $\begin{array}{c}9.0 \\
(1.4-11.5)\end{array}$ & $\begin{array}{c}12.0^{\star *} \\
(7.4-16.1)\end{array}$ & $\begin{array}{c}7.0 \\
(1.4-8.7)\end{array}$ \\
\hline & IL-15 & $\begin{array}{c}4.0^{\# \#} \\
(2.1-8.1)\end{array}$ & $\begin{array}{c}14.5^{\star \star \star} \\
(8.5-23.7)\end{array}$ & $\begin{array}{c}5.2 \\
(2-9.3)\end{array}$ & $\begin{array}{c}9.2 \\
(3.6-15.7)\end{array}$ & $\begin{array}{c}5.3 \\
(2.9-14.6)\end{array}$ & $\begin{array}{c}8.3 \\
(3.5-27.6)\end{array}$ & $\begin{array}{c}6.7 \\
(2.8-13.1)\end{array}$ \\
\hline & TGF $\alpha$ & $\begin{array}{c}1.7^{\ddagger} \\
(1.2-4.6)\end{array}$ & $\begin{array}{c}5.8^{* \star} \\
(2.9-12.4)\end{array}$ & $\begin{array}{c}2.4 \\
(1-5.1)\end{array}$ & $\begin{array}{c}3.3 \\
(1.6-7.9)\end{array}$ & $\begin{array}{c}3.1 \\
(0.8-7.9)\end{array}$ & $\begin{array}{c}4.0 \\
(2.4-40.3)\end{array}$ & $\begin{array}{c}2.7 \\
(0.8-5.7)\end{array}$ \\
\hline
\end{tabular}

Note: Data are represented as median (interquartile range) in $\mathrm{pg} / \mathrm{ml}$. $\mathrm{HC}$, healthy controls; $\mathrm{AH}$, patients with alcoholic hepatitis; HDC, heavy drinking controls. Kruskal-Wallis test with Dunn's correction for pairwise comparisons among $\mathrm{HC}, \mathrm{AH}$ patients, and $\mathrm{HDC}$ at enrolment (Day 0). Mann Whitney test comparing AH patients versus HDC at Day 180 and Day $360 .{ }^{*} p<0.05,{ }^{* *} p<$ 0.01, ${ }^{* * *} p<0.001$ for comparison between AH patients and HDC; ${ }^{\ddagger} p<0.05,{ }^{*} p<0.01,{ }^{*} p<0.001$ for comparison between $\mathrm{AH}$ patients and $\mathrm{HC}$ at Day 0. 
Table 3. Cross-sectional Analysis of Cell Surface Activation Markers in AH patients and HDC

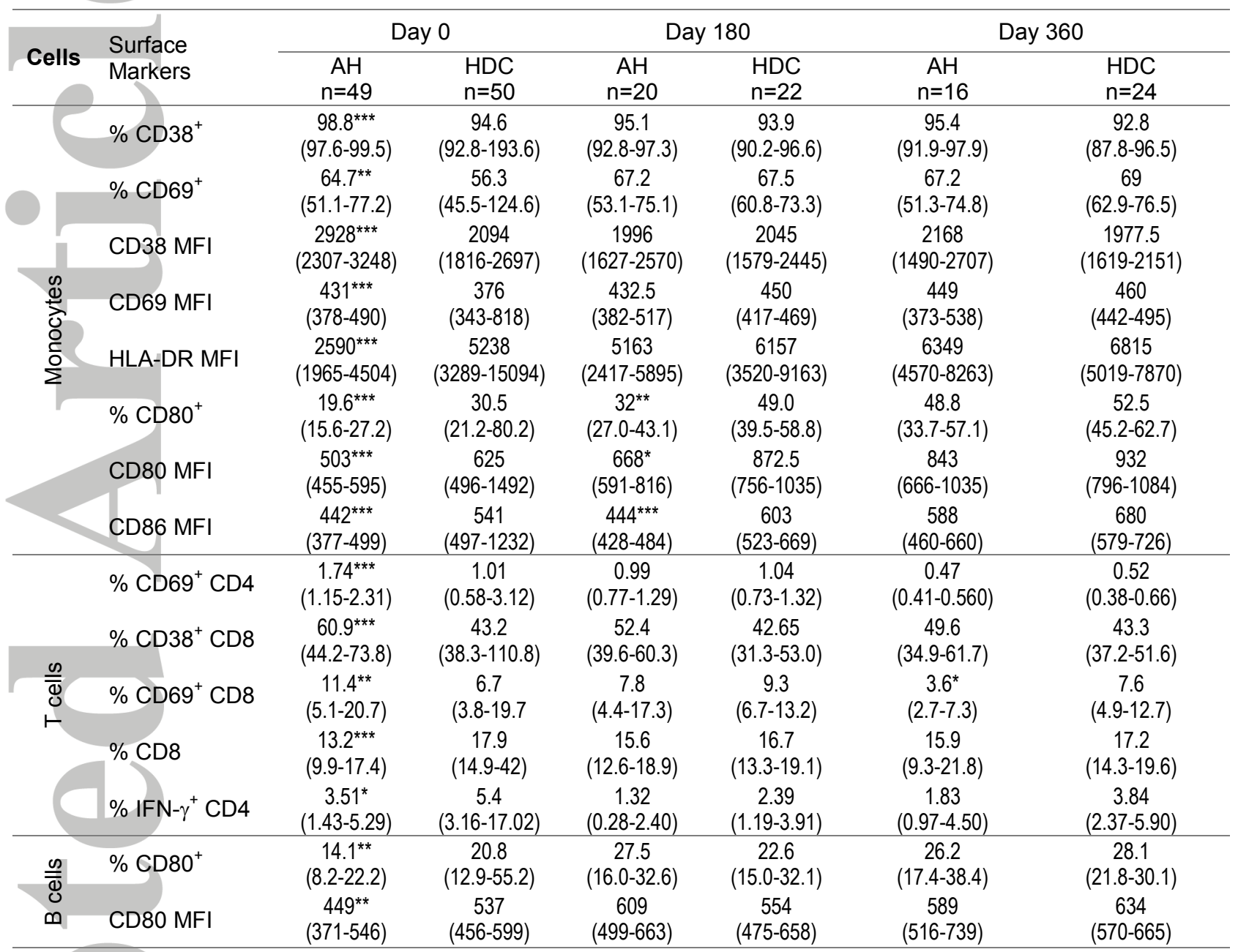

Note: Data are represented as median (interquartile range). $\mathrm{AH}$, patients with alcoholic hepatitis; HDC, heavy drinking controls; MFI: mean fluorescent intensity. Mann Whitney test comparing $\mathrm{AH}$ patients versus HDC at enrolment (Day 0), day 180 and day $360,{ }^{*} p<0.05,{ }^{* *} p<$ $0.01,{ }^{* * *} p<0.001$. 
A) Multiplex
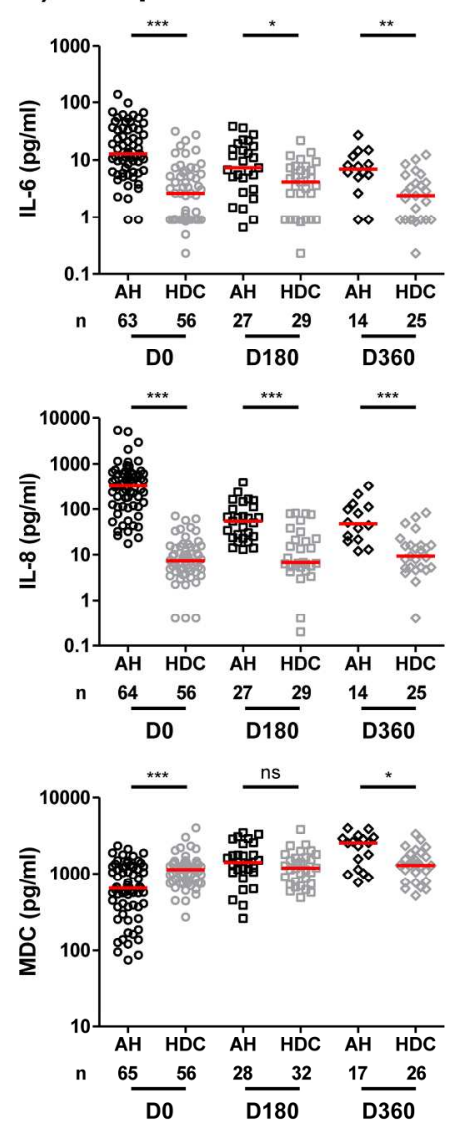

\section{B) ELISA}
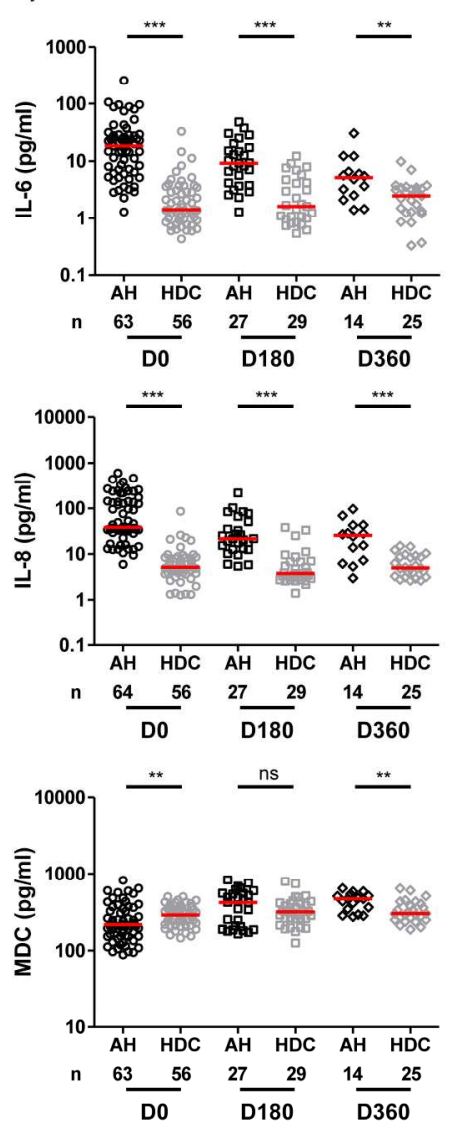

\section{C) Correlation}
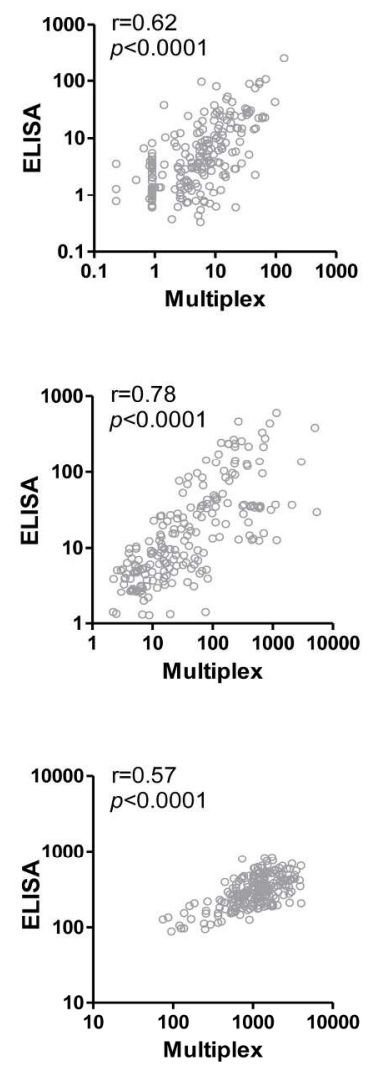

Fig. 1. Plasma levels of proinflammatory and anti-inflammatory cytokines/chemokines in AH and HDC.

Scatter plots demonstrating the plasma levels of IL-6, IL-8, and MDC in AH patients and HDC as determined by either multiplex assays (A) or ELISA (B). Mann Whitney test was used to compare the levels of these cytokines/chemokines in AH versus HDC at day 0, day 180, and day 360. (C) Spearman correlation analysis between plasma cytokine levels in all samples quantified by both multiplex assays and ELISA $(n=210)$. $r$, Spearman correlation coefficient. AH, patients with alcoholic hepatitis; HDC, heavy drinking controls; *p < $0.05 ; * * p<0.01 ; * * * p<0.001 ;$ ns, not significant; D0, day 0; D180, day 180 ; and D360, day 360 . Horizontal lines represent the median.

$194 \times 177 \mathrm{~mm}(300 \times 300 \mathrm{DPI})$

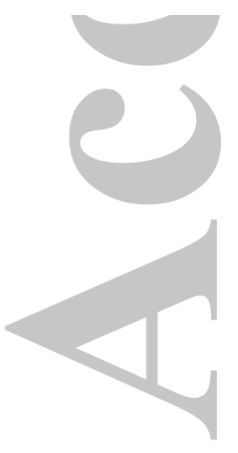



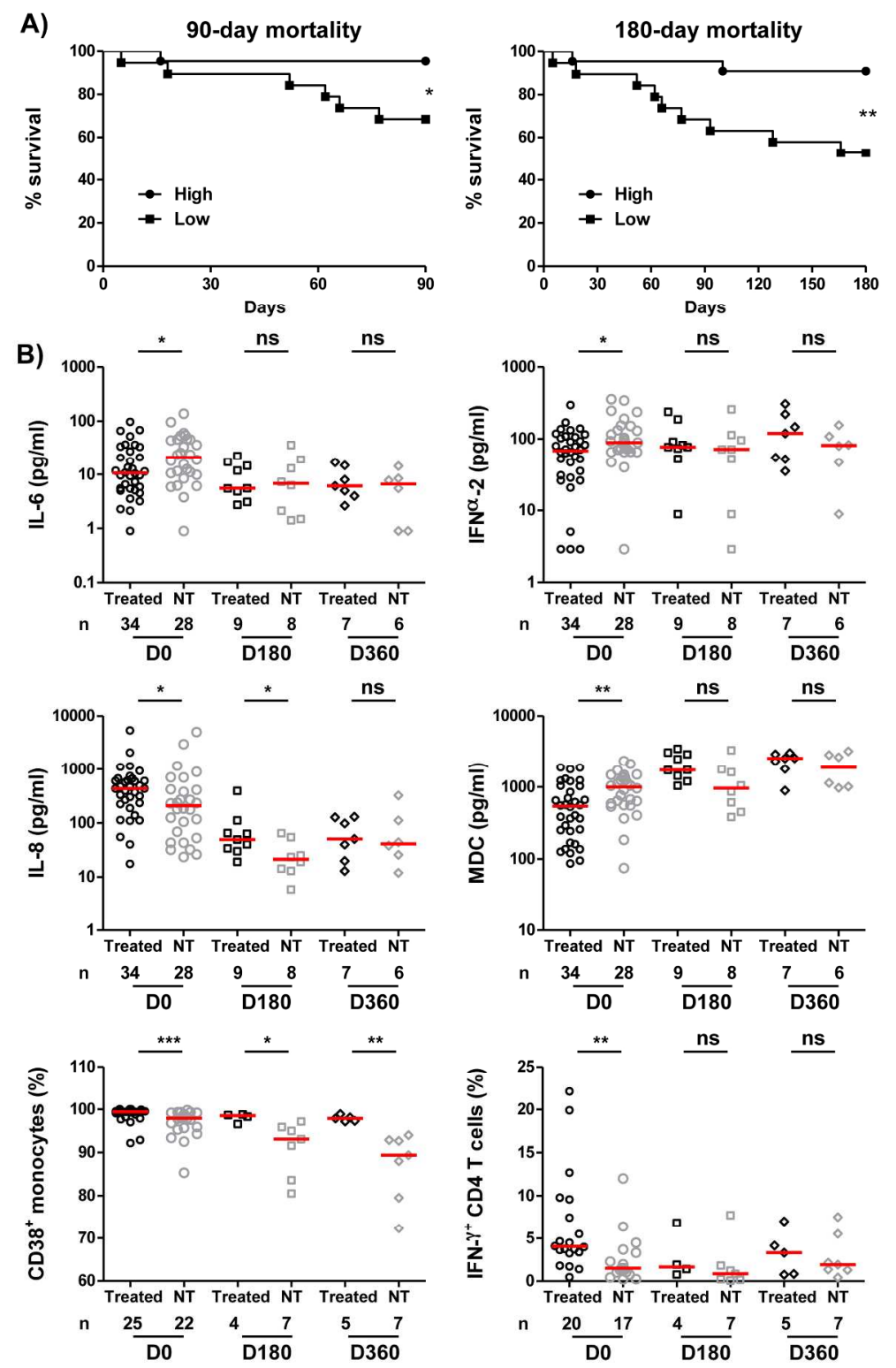

Fig. 2. Kaplan-Meier survival curves and comparison of immune markers in steroid-treated and untreated $A H$ patients. (A) Kaplan-Meier curves showing 3- and 6-month survival according to baseline CD38 expression levels on monocytes. The mean fluorescent intensity (MFI) of 2,999 was used as the cut-off to define patients with low $(n=17)$ or high $(n=18)$ CD38 expression. (B) Scatter plots of plasma IL-6, IFNa-2, IL-8, MDC levels, CD38-expressing monocytes, and IFN- $\gamma$-expressing CD4 T cells in steroid \pm pentoxifyllinetreated (Treated) and non-treated (NT) patients. Mann Whitney test for comparisons at days 0 (D0), 180 (D180), and 360 (D360). Horizontal lines represent the median; *p $<0.05 ; * *<<0.01 ;$ and ns, not significant.

$168 \times 255 \mathrm{~mm}(300 \times 300$ DPI $)$ 
A) AH
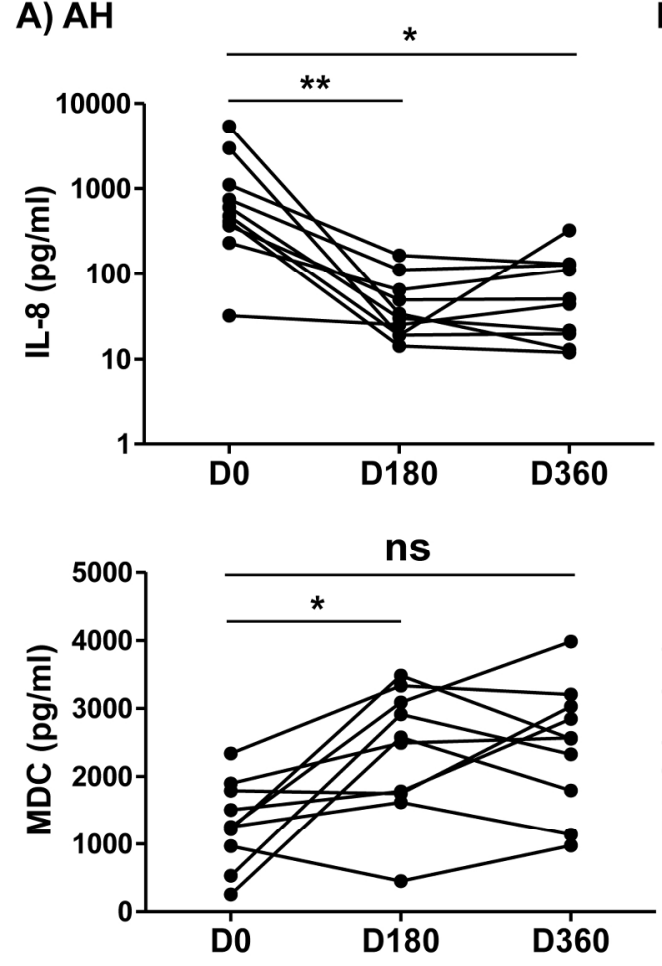

B) HDC
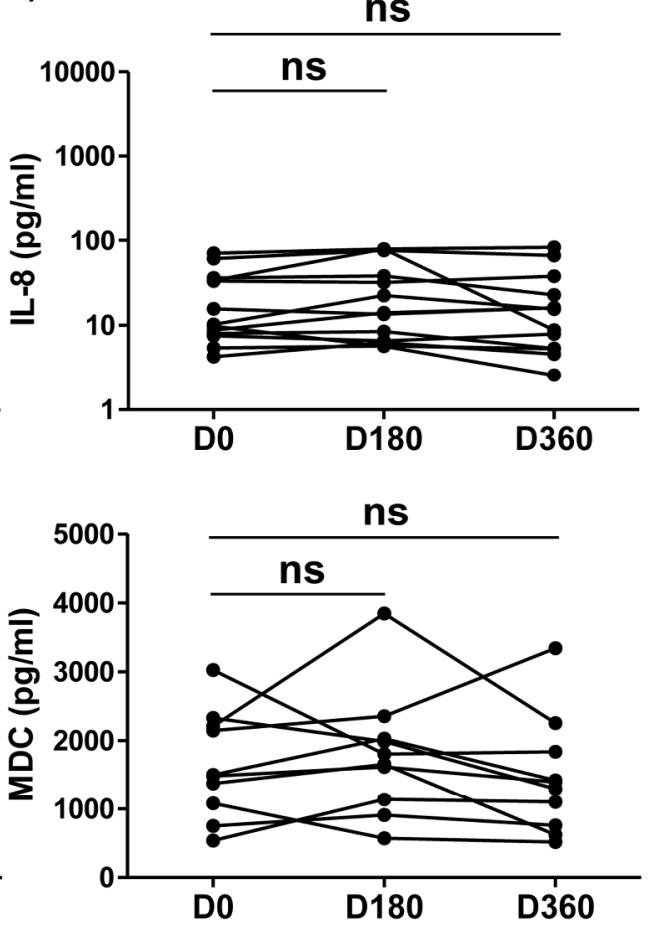

Fig. 3. Longitudinal analysis of plasma levels of IL-8 and MDC in AH patients and HDC who were abstinent from alcohol. Friedman rank sum test with Dunn's corrections for comparing cytokine/chemokine concentrations at day 0 with day 180 or day $360\left(n=10\right.$ for both AH and HDC). ${ }^{*} p<0.05, * * p<0.01, * * p$ $<0.001$. ns, not significant; D0, day 0; D180, day 180; and D360, day 360.

$$
179 \times 133 \mathrm{~mm}(300 \times 300 \text { DPI) }
$$



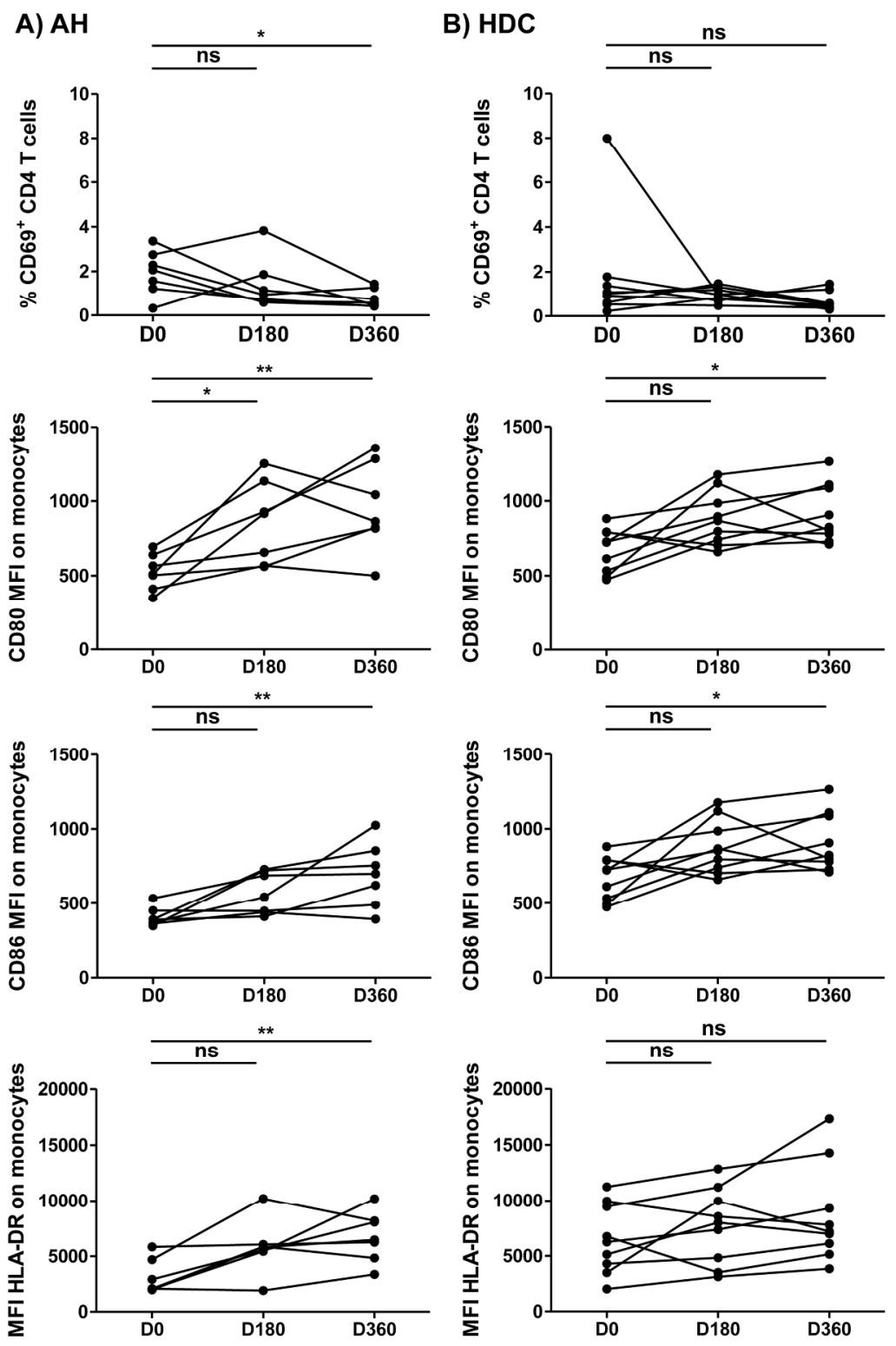

Fig. 4. Longitudinal analysis of the effects of alcohol abstinence on expression levels of cell surface markers in AH patients and HDC. Friedman rank sum test with Dunn's corrections for comparing surface marker expression at day 0 with day 180 or day 360 ( $n=7$ for $\mathrm{AH}$ and $n=9$ for HDC). $* \mathrm{p}<0.05, * * p<0.01$. ns, not significant; D0, day 0; D180, day 180; D360, day 360; and MFI, mean fluorescent intensity.

$167 \times 248 \mathrm{~mm}(300 \times 300 \mathrm{DPI})$

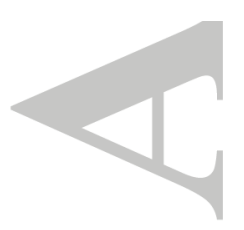




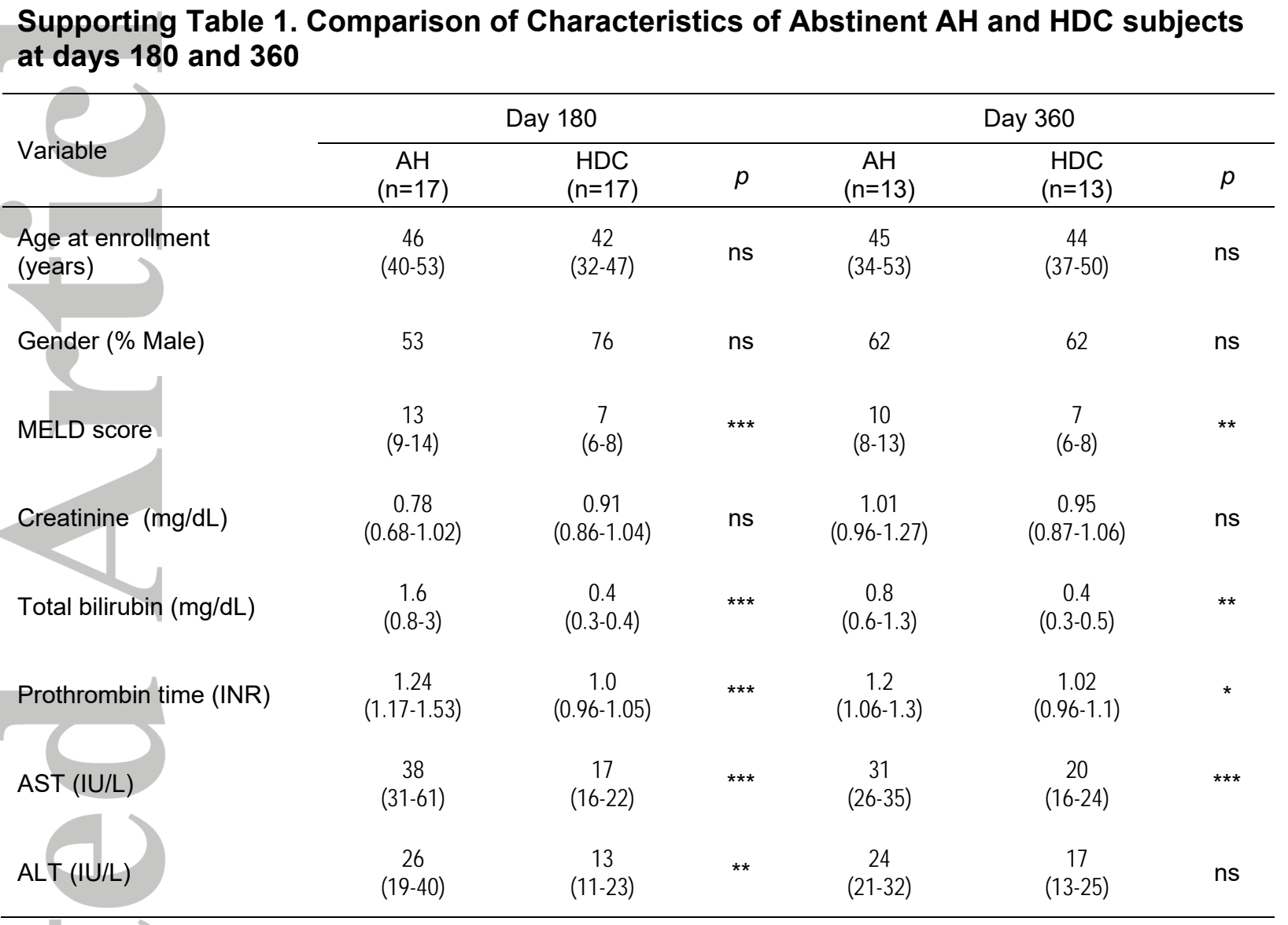

Note: Data are shown as median (interquartile range). $\mathrm{AH}$, patients with alcoholic hepatitis; HDC, heavy drinking controls; MELD, end stage liver disease; INR, international normalized ratio; $\mathrm{AST}$, aspartate aminotransferase; $\mathrm{ALT}$, alanine aminotransferase. Mann Whitney test and Chi-square test comparing $\mathrm{AH}$ patients versus HDC for continuous and categorical variables, respectively. ${ }^{*} p<0.05,{ }^{* *} p<0.01,{ }^{* * *} p<0.001$, ns: not significant. 


\begin{tabular}{|c|c|c|c|c|c|}
\hline \multirow{2}{*}{$\begin{array}{l}\text { Cytokines/ } \\
\text { Chemokines }\end{array}$} & \multicolumn{3}{|c|}{ Day 0} & \multirow{2}{*}{$\begin{array}{c}\text { Day } 180 \\
A H \text { vs HDC }\end{array}$} & \multirow{2}{*}{$\begin{array}{r}\text { Day } 360 \\
\text { AH vs HDC }\end{array}$} \\
\hline & AH vs HDC & $\mathrm{AH}$ vs $\mathrm{HC}$ & HDC vs HC & & \\
\hline IL-8 & $39.2^{* \star *}$ & $45.6^{\star * *}$ & 1.2 & $6.2^{* * *}$ & $4.6^{\star * *}$ \\
\hline IL-6 & $5.1^{* \star *}$ & $9.8^{* * *}$ & 1.9 & $1.5^{*}$ & $3.1^{* *}$ \\
\hline IL-7 & $3.8^{*}$ & $5.8^{*}$ & 1.5 & 0.8 & $1.7^{* *}$ \\
\hline $\mathrm{IL}-15$ & $2.8^{\star * *}$ & $3.7^{\star * *}$ & 1.3 & 1.7 & 1.2 \\
\hline IL-10 & $2.5^{\star \star *}$ & $5.2^{* * *}$ & 2.0 & 1.1 & $1.9^{*}$ \\
\hline TGF-a & $2.4^{* *}$ & $3.3^{*}$ & 1.4 & 1.1 & 1.5 \\
\hline IL-1B & 2.4 & 1.9 & 0.8 & 1.4 & $9.0^{*}$ \\
\hline IP-10 & $1.8^{* * *}$ & $2.3^{\star \star \star *}$ & 1.2 & $1.6^{* *}$ & 1.5 \\
\hline GM-CSF & 1.8 & 2.4 & 1.4 & 1.4 & $1.4^{*}$ \\
\hline TNFa & $1.8^{* * *}$ & $2.8^{* * *}$ & 1.6 & $2.0^{*}$ & $1.8^{* * *}$ \\
\hline IL-2 & 1.7 & 1.2 & 0.7 & 0.7 & $2.0^{*}$ \\
\hline IL-12P40 & 1.6 & 1.3 & 0.8 & 1.2 & 4.5 \\
\hline IL-1RA & 1.6 & 2.3 & 1.5 & 1.3 & 2.4 \\
\hline $\mathrm{IL}-1 \mathrm{a}$ & 1.5 & 3.0 & 2.0 & 0.7 & 1.6 \\
\hline VEGF & 1.4 & 1.1 & 0.7 & 0.9 & $1.3^{*}$ \\
\hline $\mathrm{IL}-17 \mathrm{~A}$ & 1.4 & 2.1 & 1.5 & 1.3 & $1.7^{* *}$ \\
\hline IFNa-2 & 1.4 & $2.1^{* *}$ & 1.6 & 0.9 & 1.3 \\
\hline IL12P70 & 1.3 & 3.8 & 2.8 & 1.0 & 2.1 \\
\hline Fractalkine & 1.3 & 1.6 & 1.2 & 1.2 & $2.1^{*}$ \\
\hline G-CSF & 1.3 & 2.4 & 1.9 & 0.6 & 1.4 \\
\hline MIP-1B & 1.2 & 1.4 & 1.1 & 1.0 & 1.4 \\
\hline MIP-1a & 1.2 & 0.9 & 0.7 & 1.2 & 1.4 \\
\hline FGF-2 & $1.2^{*}$ & 0.8 & 0.7 & 1.0 & $1.9^{* *}$ \\
\hline IFNy & 1.2 & 1.9 & 1.6 & 1.0 & 1.5 \\
\hline IL-9 & $1.1^{*}$ & 1.0 & 0.8 & 1.9 & $3.4^{*}$ \\
\hline MCP-1 & 1.1 & 1.2 & 1.1 & 1.1 & 0.9 \\
\hline GRO & 1.1 & 1.3 & 1.1 & 0.6 & 0.8 \\
\hline MCP-3 & 1.0 & 0.2 & 0.2 & 5.2 & 7.3 \\
\hline IL-13 & 1.0 & 0.4 & 0.4 & 1.5 & 12.8 \\
\hline IL-3 & 1.0 & 1.0 & 1.0 & 1.0 & 1.4 \\
\hline IL-4 & $1.0^{*}$ & 1.0 & 1.0 & 1.0 & 2.3 \\
\hline IL-5 & 1.0 & 2.0 & 2.0 & 1.1 & 1.6 \\
\hline TNFB & 1.0 & 0.6 & 0.6 & 2.1 & 17.8 \\
\hline Flt-3L & 1.0 & 0.5 & 0.5 & 2.5 & 3.3 \\
\hline Eotaxin & 0.9 & 1.1 & 1.2 & 0.9 & 0.8 \\
\hline SCD40L & 0.8 & 0.9 & 1.2 & 1.1 & 0.9 \\
\hline EGF & 0.8 & $0.4^{* *}$ & 0.6 & 1.0 & 1.0 \\
\hline MDC & $0.6^{* * *}$ & 0.7 & 1.3 & 1.2 & $2.0^{*}$ \\
\hline
\end{tabular}

Note: $\mathrm{AH}$, patients with alcoholic hepatitis; $\mathrm{HDC}$, heavy drinking controls; $\mathrm{HC}$, healthy controls. Kruskal-Wallis test with Donn's correction for pairwise comparison among AH patients, HDC, and $\mathrm{HC}$ at baseline (Day 0). Mann Whitney test comparing AH patients versus HDC at day 180 and day 360. D0: $A H$ patients $n=65, H D C n=61$; 180 : $A H$ patients $n=28, H D C n=32 ; D 360: A H$ patients $n=17, \mathrm{HDC} n=26 ; \mathrm{HC} n=20 .{ }^{*} p<0.05,{ }^{* *} p<0.01,{ }^{* * *} p<0.001$. 


\begin{tabular}{|c|c|c|c|c|}
\hline Cells & Surface Marker & Day 0 & Day 180 & Day 360 \\
\hline & $\% \mathrm{CD}^{2} 8^{+}$ & $1.04^{* * *}$ & 1.01 & 1.03 \\
\hline & $\% \mathrm{CD} 9^{+}$ & $1.15^{\star *}$ & 1.00 & 0.97 \\
\hline & CD38 MFI & $1.4^{* * *}$ & 0.98 & 1.10 \\
\hline & CD69 MFI & $1.15^{\star * *}$ & 0.96 & 0.98 \\
\hline & HLA-DR MFI & $0.49^{* * *}$ & 0.84 & 0.93 \\
\hline & $\% \mathrm{CD}^{\circ} 0^{+}$ & $0.64^{* * *}$ & $0.65^{\star *}$ & 0.93 \\
\hline & CD80 MFI & $0.81^{* * *}$ & $0.77^{*}$ & 0.90 \\
\hline & CD86 MFI & $0.82^{* * *}$ & $0.74^{* \star \star}$ & 0.86 \\
\hline & $\% \mathrm{CD}^{2} 9^{+} \mathrm{CD} 4$ & $1.73^{\star \star *}$ & 0.96 & 0.90 \\
\hline & $\% \mathrm{CD}^{2} 8^{+} \mathrm{CD} 8$ & $1.41^{* * *}$ & 1.23 & 1.15 \\
\hline & $\% \mathrm{CD}^{2} 9^{+} \mathrm{CD} 8$ & $1.70^{* \star}$ & 0.84 & $0.48^{*}$ \\
\hline & $\%$ CD4 & 1.03 & 1.20 & 1.05 \\
\hline & $\%$ CD8 & $0.77^{* \star *}$ & 0.89 & 0.72 \\
\hline & $\%$ IFN- $\gamma^{+}$CD4 & $0.65^{*}$ & 0.55 & 0.48 \\
\hline T & $\% \mathrm{IFN}-\gamma^{+} \mathrm{CD} 8$ & 0.77 & 0.89 & 0.72 \\
\hline & $\% \mathrm{CD}^{\circ} 0^{+}$ & $0.68^{* *}$ & 1.21 & 0.93 \\
\hline & CD80 MFI & $0.84^{* *}$ & 1.10 & 0.93 \\
\hline & HLA-DR MFI & 0.80 & 1.21 & 0.97 \\
\hline
\end{tabular}

Note: $\mathrm{AH}$, alcoholic hepatitis; $\mathrm{HDC}$, heavy drinking controls. Mann Whitney test comparing $\mathrm{AH}$ patients versus HDC at baseline (Day 0), day 180 and day 360. Day 0: AH patients $n=49, \mathrm{HDC}$ $n=50$; Day 180: $A H$ patients $n=20, \operatorname{HDC} n=22$; Day 360: AH patients $n=16, \operatorname{HDC} n=24$. ${ }^{*} p<$ $0.05,{ }^{* *} p<0.01,{ }^{* * *} p<0.001$.

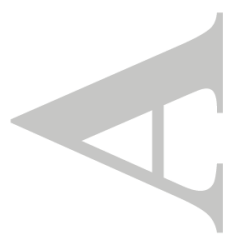




\section{Supporting Table 4. Correlation Coefficients and Statistical Significance between Immune Parameters and Clinical and Biochemical Data in AH Patients}

\begin{tabular}{|c|c|c|c|c|c|c|c|c|}
\hline & $\begin{array}{l}\text { Immune } \\
\text { markers }\end{array}$ & $\begin{array}{l}\text { MELD } \\
\text { score }\end{array}$ & Creatinine & $\begin{array}{l}\text { Total } \\
\text { bilirubin }\end{array}$ & INR & ALT & AST & $\begin{array}{l}\text { \# of drinks } \\
\text { in the } \\
\text { prior } 30 \\
\text { days }\end{array}$ \\
\hline $\begin{array}{l}\text { Neutro } \\
\text { phils }\end{array}$ & Count & $0.46^{* * *}$ & ns & $0.45^{\star \star *}$ & $0.3^{*}$ & ns & $0.26^{*}$ & ns \\
\hline \multirow{6}{*}{ 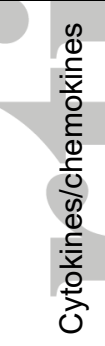 } & IL-6 & $0.42^{* * *}$ & ns & $0.43^{* * *}$ & $0.31^{* *}$ & ns & $0.39^{* * *}$ & ns \\
\hline & IL-8 & $0.65^{\star * *}$ & $0.32^{*}$ & $0.74^{* * *}$ & $0.45^{\star * *}$ & $0.21^{*}$ & $0.58^{* * *}$ & $0.52^{* * *}$ \\
\hline & $\mathrm{IL}-15$ & $0.24^{*}$ & ns & $0.29^{* *}$ & $0.23^{*}$ & ns & $0.24^{* *}$ & ns \\
\hline & MDC & $-0.46^{\star * *}$ & ns & $-0.57^{* * *}$ & $-0.38^{* * *}$ & $-0.28^{\star *}$ & $-0.44^{* * *}$ & $-0.43^{* * *}$ \\
\hline & TGF- $\alpha$ & $0.24^{*}$ & ns & $0.29^{*}$ & $0.27^{* *}$ & ns & ns & ns \\
\hline & $\mathrm{TNF} \alpha$ & ns & $0.29 * *$ & ns & ns & ns & ns & ns \\
\hline \multirow{5}{*}{ 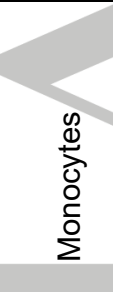 } & \% CD38 & $0.54^{* * *}$ & ns & $0.58^{* * *}$ & $0.53^{* * *}$ & ns & $0.26^{*}$ & $0.36^{\star * *}$ \\
\hline & CD38 MFI & $0.38^{* * *}$ & ns & $0.43^{* * *}$ & $0.36^{\star * *}$ & ns & $0.32^{* *}$ & $0.29^{* *}$ \\
\hline & \% CD80+ & $-0.35^{\star *}$ & ns & $-0.44^{* * *}$ & ns & $-0.31^{* *}$ & $-0.49^{* * *}$ & $-0.33^{* *}$ \\
\hline & CD80 MFI & $-0.35^{\star *}$ & ns & $-0.44^{* * *}$ & ns & $-0.3^{* *}$ & $-0.48^{* * *}$ & $-0.33^{* *}$ \\
\hline & CD86 MFI & ns & ns & ns & ns & $-0.25^{\star}$ & $-0.32^{* *}$ & ns \\
\hline & $\begin{array}{l}\text { HLA-DR } \\
\text { MFI }\end{array}$ & $-0.36^{* * *}$ & ns & $-0.42^{* * *}$ & $-0.27^{*}$ & ns & $-0.35^{\star * *}$ & ns \\
\hline \multirow{2}{*}{$\begin{array}{l}\infty \\
\bar{D} \\
0 \\
\infty\end{array}$} & $\%$ CD80 & $-0.26^{*}$ & ns & $-0.3^{* *}$ & ns & ns & $-0.33^{\star *}$ & $-0.22^{*}$ \\
\hline & CD80 MFI & $-0.30^{\star *}$ & ns & $-0.33^{* *}$ & ns & ns & $-0.35^{\star * *}$ & $-0.24^{*}$ \\
\hline & $\begin{array}{l}\text { CD69 }^{+} \\
\text {CD4 }\end{array}$ & $0.40^{\star * *}$ & ns & $0.50^{* * *}$ & $0.30^{* *}$ & $0.28^{* *}$ & $0.45^{\star * *}$ & $0.38^{* * *}$ \\
\hline & \% CD8 & $-0.28^{*}$ & ns & $-0.27^{*}$ & $-0.26^{*}$ & ns & ns & ns \\
\hline & $\begin{array}{l}\% \text { CD38+ } \\
\text { CD8 }\end{array}$ & $0.30^{* *}$ & ns & $0.34^{* *}$ & ns & ns & ns & ns \\
\hline & $\begin{array}{l}\% \text { CD69+ } \\
\text { CD8 }\end{array}$ & ns & ns & $0.24^{*}$ & ns & ns & $0.36^{* * *}$ & ns \\
\hline
\end{tabular}

Note: AH, alcoholic hepatitis; MELD, end stage liver disease; INR, international relative ratio for prothrombin time; AST, aspartate aminotransferase; ALT, alanine aminotransferase. The numbers represent Spearman's coefficients, ${ }^{*} p<0.05,{ }^{* *} p<0.01,{ }^{* * *} p<0.001$, ns: nonsignificant. Negative numbers represent negative correlations. $\mathrm{N}=63$ for neutrophil counts, $\mathrm{n}=108$ for cytokines/chemokines, $\mathrm{n}=82$ for cellular markers. 


\section{Supporting Table 5. Fold Changes in Median Levels of Immune Markers between Corticosteroids \pm pentoxifylline-treated and -untreated AH Patients}

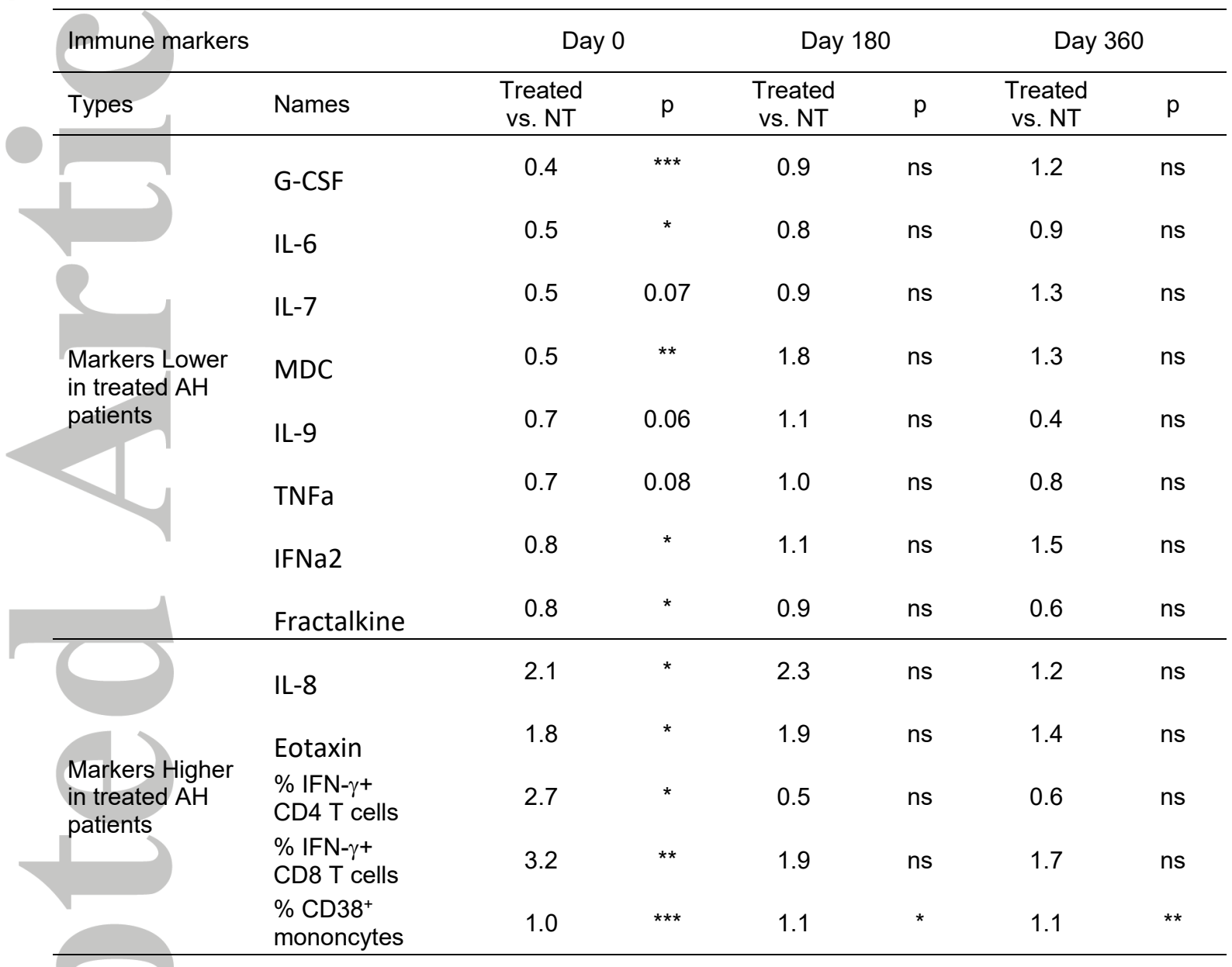

Note: $\mathrm{AH}$, alcoholic hepatitis; Treated, patients treated with corticosteroids alone or with both corticosteroids and pentoxifylline at study entry; NT, AH patients not treated with the drugs. Day 180 and Day 360 samples were from AH patients who were abstinent at follow up. Mann Whitney test comparing treated versus untreated $\mathrm{AH}$ patients at baseline (Day 0), day 180 and day 360. Day 0: Treated $n=25-34$, NT n=22-28; Day 180: Treated $n=4-9, N T n=7-8$; Day 360: Treated $n=5-7, \mathrm{NT} n=6-7 .{ }^{*} p<0.05,{ }^{* *} p<0.01,{ }^{* * *} p<0.001$. 
Supporting Table 6. Comparison of Plasma Cytokine/chemokine Levels in Abstinent Subjects at Days 180 and 360

\begin{tabular}{|c|c|c|c|c|c|c|c|}
\hline \multicolumn{2}{|c|}{ Cytokines/chemokines } & \multicolumn{3}{|c|}{ Day 180} & \multicolumn{3}{|c|}{ Day 360} \\
\hline & Names & $\begin{array}{c}\mathrm{AH} \\
(n=17)\end{array}$ & $\begin{array}{l}\text { HDC } \\
(n=17)\end{array}$ & $p$ & $\begin{array}{c}\mathrm{AH} \\
(n=13)\end{array}$ & $\begin{array}{l}\text { HDC } \\
(n=13)\end{array}$ & $p$ \\
\hline \multirow{5}{*}{ Pro-inflammatory } & IFN $\alpha 2$ & $\begin{array}{c}77.5 \\
(72.0-96.2)\end{array}$ & $\begin{array}{c}77.5 \\
(46.8-97.4)\end{array}$ & ns & $\begin{array}{c}82.9 \\
(51.9-147.2)\end{array}$ & $\begin{array}{c}72 \\
(60.7-93.4)\end{array}$ & ns \\
\hline & $\mathrm{TNF} \alpha$ & $\begin{array}{c}27.7 \\
(15.5-32.0)\end{array}$ & $\begin{array}{c}8.3 \\
(5.6-13.4)\end{array}$ & $* *$ & $\begin{array}{c}27.3 \\
(21.8-45.0)\end{array}$ & $\begin{array}{c}11.9 \\
(5.1-17.9)\end{array}$ & ** \\
\hline & IL-6 & $\begin{array}{c}7.3 \\
(4.9-19.3)\end{array}$ & $\begin{array}{c}4.2 \\
(0.9-7.8)\end{array}$ & * & $\begin{array}{c}6.2 \\
(4.0-8.5)\end{array}$ & $\begin{array}{c}2.4 \\
(1.4-5.7)\end{array}$ & * \\
\hline & IL-8 & $\begin{array}{c}40.4 \\
(23.5-65.2)\end{array}$ & $\begin{array}{c}8.3 \\
(5.8-47.6)\end{array}$ & * & $\begin{array}{c}44.2 \\
(25.7-111.4)\end{array}$ & $\begin{array}{c}9.4 \\
(5.4-22.8)\end{array}$ & ** \\
\hline & IP10 & $\begin{array}{c}1317 \\
(882-1764)\end{array}$ & $\begin{array}{c}648 \\
(324-1041)\end{array}$ & $* *$ & $\begin{array}{c}1169 \\
(861-1274)\end{array}$ & $\begin{array}{c}689 \\
(472-1214)\end{array}$ & ns \\
\hline \multirow{4}{*}{ Anti-inflammatory } & IL-4 & $\begin{array}{c}8.5 \\
(4.5-18.4)\end{array}$ & $\begin{array}{c}4.5 \\
(4.5-8.1)\end{array}$ & ns & $\begin{array}{c}8.7 \\
(4.5-31.7)\end{array}$ & $\begin{array}{c}4.5 \\
(4.5-8.7)\end{array}$ & ns \\
\hline & IL-9 & $\begin{array}{c}2.8 \\
(1.2-5.6)\end{array}$ & $\begin{array}{c}1.9 \\
(1.2-4.0)\end{array}$ & ns & $\begin{array}{c}4.1 \\
(1.2-15.3)\end{array}$ & $\begin{array}{c}1.2 \\
(0.9-1.9)\end{array}$ & ns \\
\hline & IL-10 & $\begin{array}{c}10.9 \\
(2.8-27.4)\end{array}$ & $\begin{array}{c}8.3 \\
(1.1-11.4)\end{array}$ & ns & $\begin{array}{c}17.5 \\
(7.6-34.2)\end{array}$ & $\begin{array}{c}9.3 \\
(7.6-11.7)\end{array}$ & ns \\
\hline & MDC & $\begin{array}{c}1442 \\
(1056-2492)\end{array}$ & $\begin{array}{c}1201 \\
(718-1575)\end{array}$ & ns & $\begin{array}{c}2552 \\
(1137-2845)\end{array}$ & $\begin{array}{c}1297 \\
(1099-1509)\end{array}$ & ns \\
\hline \multirow{5}{*}{ Growth factors } & EGF & $\begin{array}{c}33.9 \\
(13.1-52.8)\end{array}$ & $\begin{array}{c}35.8 \\
(18.1-77.6)\end{array}$ & ns & $\begin{array}{c}42.1 \\
(28.4-118)\end{array}$ & $\begin{array}{c}64.6 \\
(41.6-108.1)\end{array}$ & ns \\
\hline & FGF2 & $\begin{array}{c}102.8 \\
(66.3-122)\end{array}$ & $\begin{array}{c}91.9 \\
(62.4-104.3)\end{array}$ & ns & $\begin{array}{c}109.1 \\
(83.6-225.3)\end{array}$ & $\begin{array}{c}83.6 \\
(58.2-91.9)\end{array}$ & * \\
\hline & IL-7 & $\begin{array}{c}7.2 \\
(4.7-10.9)\end{array}$ & $\begin{array}{c}5.5 \\
(1.4-10.1)\end{array}$ & ns & $\begin{array}{c}12 \\
(8.4-18.9)\end{array}$ & $\begin{array}{c}7.4 \\
(1.4-8.7)\end{array}$ & * \\
\hline & IL-15 & $\begin{array}{c}10.7 \\
(5.3-23.1)\end{array}$ & $\begin{array}{c}6.4 \\
(1.3-17.9)\end{array}$ & ns & $\begin{array}{c}6.5 \\
(3.5-27.6)\end{array}$ & $\begin{array}{c}4.5 \\
(2.4-13.3)\end{array}$ & ns \\
\hline & TGF $\alpha$ & $\begin{array}{c}4.7 \\
(2.7-13) \\
\end{array}$ & $\begin{array}{c}2.5 \\
(0.8-16.1) \\
\end{array}$ & ns & $\begin{array}{c}4.0 \\
(2-40.3) \\
\end{array}$ & $\begin{array}{c}5.1 \\
(2.2-13.6) \\
\end{array}$ & ns \\
\hline
\end{tabular}

Note: Data are represented as median (interquartile range) in $\mathrm{pg} / \mathrm{ml}$. AH, patients with alcoholic hepatitis; HDC, heavy drinking controls. Mann Whitney test comparing AH patients vs HDC at day 180 and day $360 .{ }^{*} p<0.05,{ }^{* *} p<0.01$, ns: not significant. 


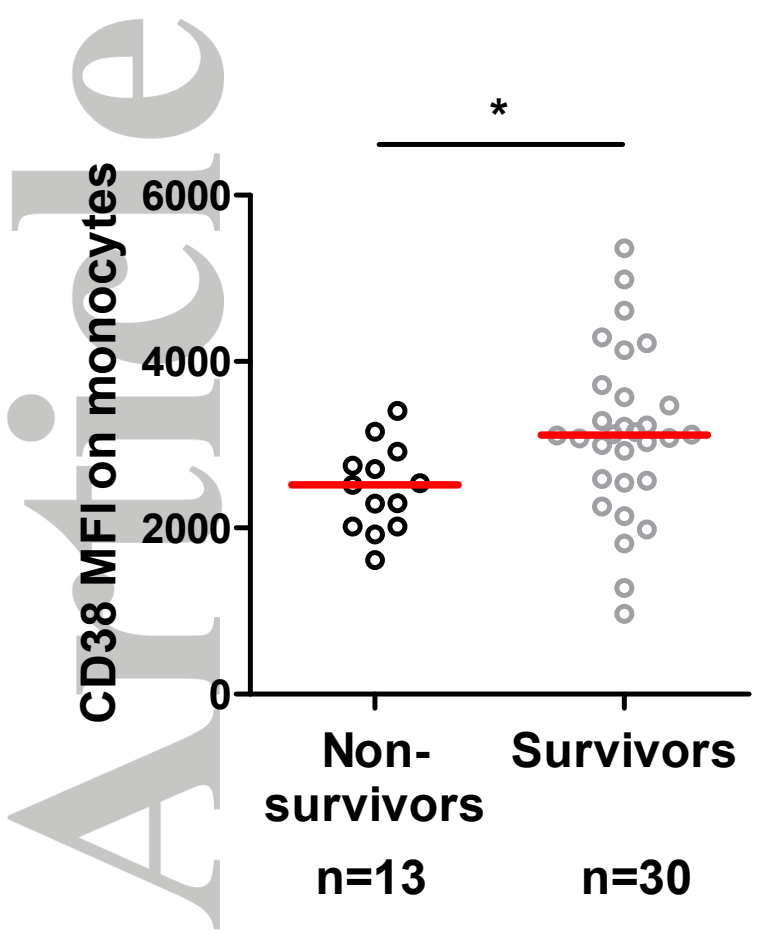

Supporting Fig. S1. CD38 expression levels on monocytes predicted AH mortality. Scatter plot of baseline CD38 expression levels on monocytes in AH patients who died within 6 months after recruitment (non-survivors) and those survived (survivors). Horizontal lines represent the median. Mann Whitney test was used for the statistical analysis. ${ }^{*} p<0.05$.

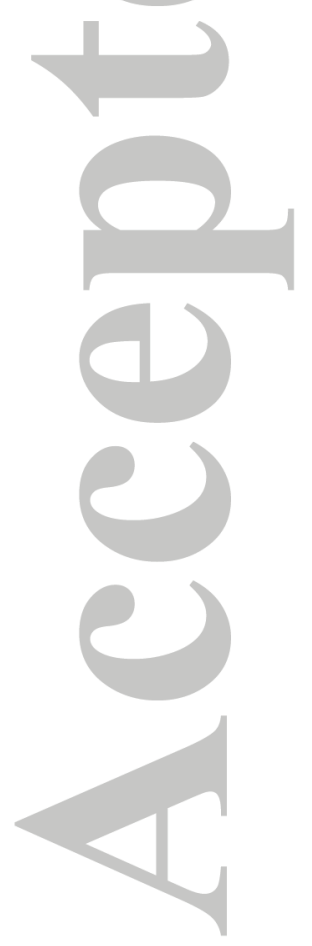



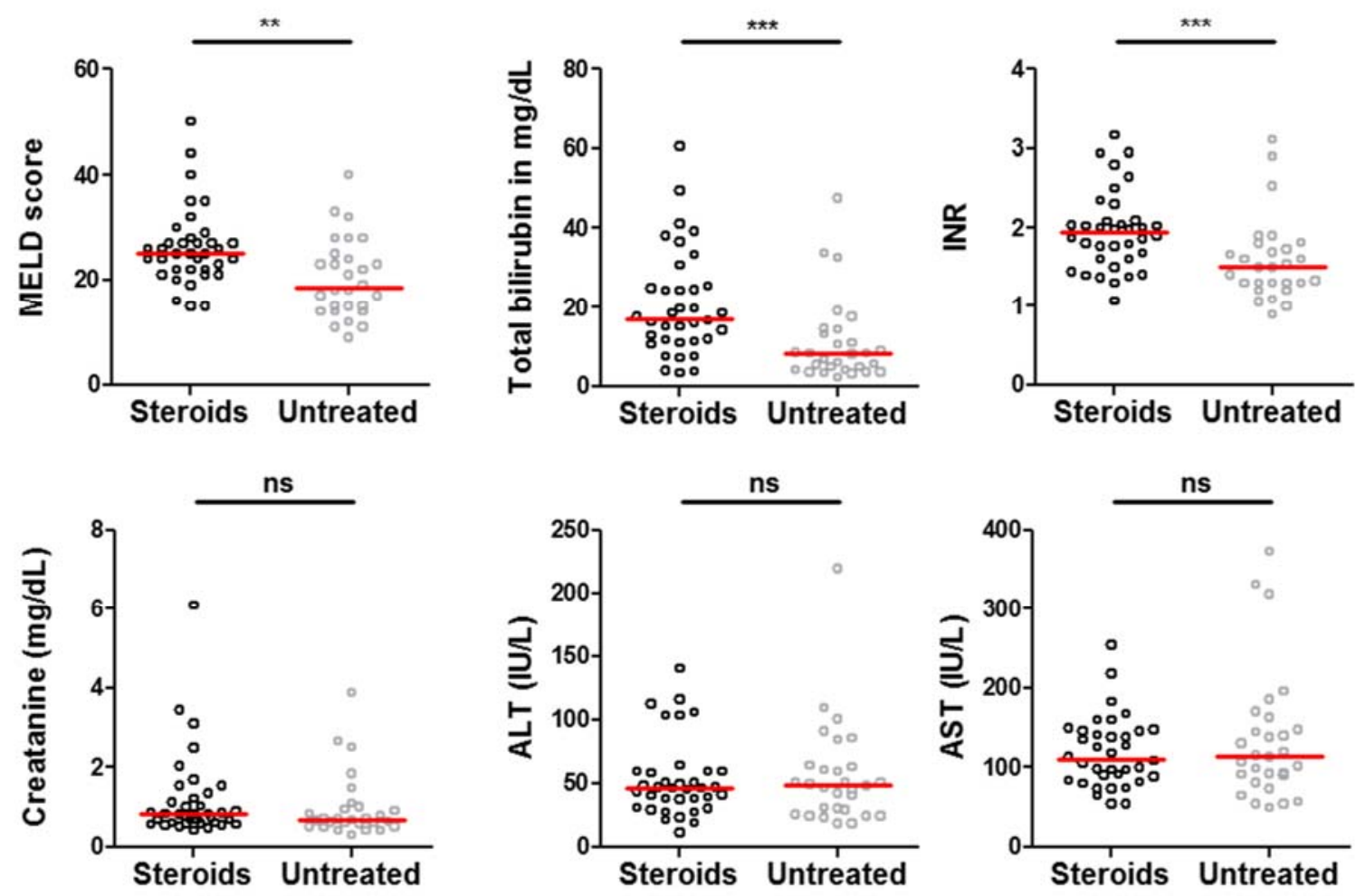

Supporting Fig. S2. Differences in clinical characteristics between AH patients treated with prednisone \pm pentoxifylline and untreated $\mathrm{AH}$ patients at enrolment. Mann Whitney test was used to compare MELD score, total bilirulin, international normalized ratio for prothrombin time (INR), creatinine, alanine aminotransferase (ALT), and aspartate aminotransferase ( AST) $(n=36$, for treated and $n=28-29$ for untreated). Horizontal line represent the median. Mann Whitney test was used for the statistical analysis. ${ }^{*} p<0.05,{ }^{* *} p<$ $0.01 ;{ }^{* * *} p<0.001$. 
$\mathrm{AH}$

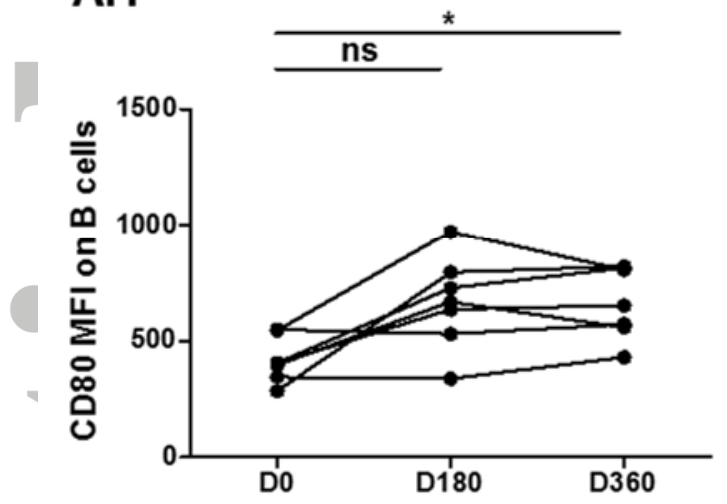

HDC

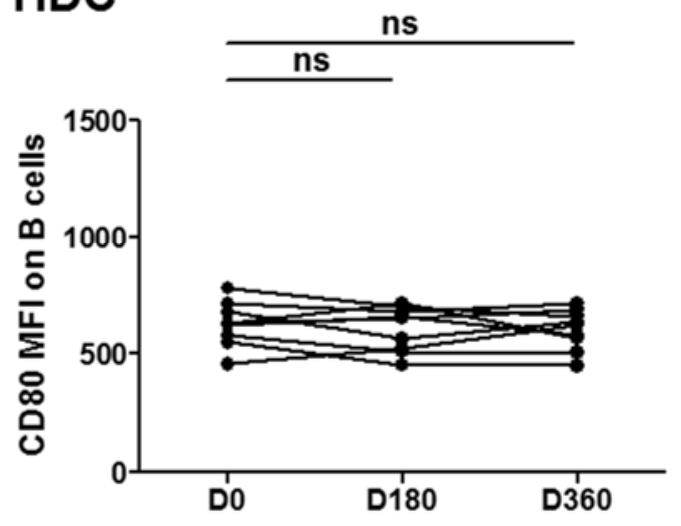

Supporting Fig. S3. Recovery of CD80 expression on B cells in AH patients after alcohol cessation. Longitudinal analysis of CD80 expression levels on B cells in AH patients and HDC controls. Friedman rank sum test comparing surface marker expression at day 0 with day 180 and 360 (Dunn's corrections for multiple testing of data, $n=7$ for $\mathrm{AH}$ patients and $n=9$ for HDC). ${ }^{*} p<0.05 . n s$, not significant. MFI, mean fluorescent intensity. 